Published in final edited form as:

Annu Rev Cell Dev Biol. 2006 ; 22: 339-373.

\title{
Epidermal Stem Cells of the Skin
}

\author{
Cédric Blanpain and Elaine Fuchs * \\ Howard Hughes Medical Institute, The Rockefeller University, New York, New York 10021; email: \\ fuchslb@rockefeller.edu
}

\begin{abstract}
The skin constantly renews itself throughout adult life, and the hair follicle undergoes a perpetual cycle of growth and degeneration. Stem cells (SCs) residing in the epidermis and hair follicle ensure the maintenance of adult skin homeostasis and hair regeneration, but they also participate in the repair of the epidermis after injuries. We summarize here the current knowledge of epidermal SCs of the adult skin. We discuss their fundamental characteristics, the methods recently designed to isolate these cells, the genes preferentially expressed in the multipotent SC niche, and the signaling pathways involved in SC niche formation, SC maintenance, and activation. Finally, we speculate on how the deregulation of these pathways may lead to cancer formation.
\end{abstract}

\section{Keywords}

hair follicle; multipotency; self-renewal; cell fate determination; Wnt signaling; Bmp; cancer

\section{INTRODUCTION}

Skin and its appendages ensure a number of critical functions necessary for animal survival. Skin protects animals from water loss, temperature change, radiation, trauma, and infections, and it allows animals to perceive their environment through tactile sense. Through camouflage, the skin provides protection against predators, and it also serves as decoration for social and reproductive behavior.

Adult skin is composed of a diverse organized array of cells emanating from different embryonic origins. In mammals, shortly after gastrulation, the neurectoderm cells that remain at the embryo surface become the epidermis, which begins as a single layer of unspecified progenitor cells. During development, this layer of cells forms a stratified epidermis (sometimes called interfollicular epidermis), the hair follicles (HRs), sebaceous glands, and, in nonhaired skin, the apocrine (sweat) glands. Mesoderm-derived cells contribute to the collagen-secreting fibroblasts of the underlying dermis, the dermovasculature that supplies nutrients to skin, arrector pili muscles that attach to each hair follicle (HF), the subcutaneous fat cells, and the immune cells that infiltrate and reside in the skin. Neural crest-derived cells contribute to melanocytes, sensory nerve endings of the skin, and the dermis of the head. Overall, approximately 20 different cell types reside within the skin.

In the adult, many different types of stem cells (SCs) function to replenish these various cell types in skin as it undergoes normal homeostasis or wound repair. Some SCs (e.g., those that replenish lymphocytes) reside elsewhere in the body. Others (e.g., melanoblasts and epidermal $\mathrm{SCs}$ ) reside within the skin itself. This review concentrates primarily on epidermal SCs, which possess two essential features common to all SCs: They are able to self-renew for extended

\footnotetext{
*Corresponding author.
} 
periods of time, and they differentiate into multiple lineages derived from their tissue origin (Weissman et al. 2001).

\section{ESTABLISHMENT AND STRATIFICATION OF SKIN EPITHELIUM}

Mature epidermis is a stratified squamous epithelium whose outermost layer is the skin surface. Only the innermost (basal) layer is mitotically active. The basal layer produces, secretes, and assembles an extracellular matrix (ECM), which constitutes much of the underlying basement membrane that separates the epidermis from the dermis. The most prominent basal ECM is laminin5, which utilizes $\alpha 3 \beta 1$-integrin for its assembly. As cells leave the basal layer and move outward toward the skin surface, they withdraw from the cell cycle, switch off integrin and laminin expression, and execute a terminal differentiation program. In the early stages of producing spinous and granular layers, the program remains transcriptionally active. However, it culminates in the production of dead flattened cells of the cornified layer (squames) that are sloughed from the skin surface, continually being replaced by inner cells moving outward (Figure 1).

Matrix, proliferative compartment of the growing hair follicle containing progenitor cells that terminally differentiate to give rise to the hair shaft or the channel surrounding it.

The major structural proteins of the epidermis are keratins, which assemble as obligate heterodimers into a network of 10-nm keratin intermediate filaments (IFs) that connect to $\alpha 6 \beta 4$-integrin-containing hemidesmosomes that anchor the base of the epidermis to the laminin5-rich, assembled ECM. Keratin IFs also connect to intercellular junctions called desmosomes, composed of a core of desmosomal cadherins. Together, these connections to keratin IFs provide an extensive mechanical framework to the epithelium (reviewed in Omary et al. 2004). The basal layer is typified by the expression of keratins K5 and K14 (also K15 in the embryo), whereas the intermediate suprabasal (spinous) layers express K1 and K10.

Desmosomes connected to K1/K10 IFs are especially abundant in suprabasal cells, whereas basal cells possess a less robust network of desmosomes and K5/K14. Rather, basal cells utilize a more dynamic cytoskeletal network of microtubules and actin filaments that interface through $\beta$-and $\alpha$-catenins to E-cadherin-mediated cell-cell (adherens) junctions, in addition to the $\alpha \beta 1$ integrin-mediated cell-ECM junctions (reviewed in Green et al. 2005, Perez-Moreno et al. 2003). Filaggrin and loricrin are produced in the granular layer. The cornified envelope seals the epidermal squames and provides the barrier that keeps microbes out and essential fluids in (Candi et al. 2005, Fuchs 1995) (Figure 1). The program of terminal differentiation in the epidermis is governed by a number of transcription factor families, including AP2, AP1, C/ EBPs, Klfs, PPARs, and Notch (reviewed in Dai \& Segre 2004).

Although the molecular mechanisms underlying the process of epidermal stratification are still unfolding, several studies have recently provided clues as to how this might happen. Increasing evidence suggests the transcription factor p63 might be involved. Mice null for the gene encoding p63 present an early block in the program of epidermal stratification (Mills et al. 1999, Yang et al. 1999).

There are several possible mechanisms by which stratification could be achieved with an inner layer of mitotically active cells and suprabasal differentiating layers. In the first mechanism, a proliferating basal cell progressively weakens its attachment to the basement membrane and to its neighbors and is pushed off the basal layer and up into the spinous layer. In vitro studies demonstrated that this process, referred to as delamination, effectively allows stratification (Vaezi et al. 2002, Watt \& Green 1982). A possible alternative to delamination is that basal cells in a stratifying tissue might orient their mitotic plane of division perpendicular to the 
underlying basement membrane, which would consequently place one of the two daughter cells in the suprabasal layer.

Recent studies in mice suggest that during embryonic development in skin, the majority of mitotic cells within the epidermis go from having their spindle plane parallel to the basement membrane to a perpendicular orientation (Lechler \& Fuchs 2005, Smart 1970). In these perpendicular orientations, the apical centriole associates with a complex containing Nuclear Mitotic Apparatus protein, partitioning-defective protein 3, atypical protein kinase C, Inscuteable, and partner of inscuteable. The association with this cortical complex is intriguing because most of these evolutionarily conserved proteins have been shown genetically to be essential for the asymmetric cell divisions that occur in Drosophila neuroblasts and in Caenorhabditis elegans embryos (Cowan \& Hyman 2004, Wodarz 2005). Although many features of the underlying mechanism remain to be addressed, proper spindle orientation appears to require $\beta 1$-integrin and $\alpha$-catenin, further underscoring the importance of basement membrane and adherens junctions in the establishment of epidermal polarity and tissue architecture (Lechler \& Fuchs 2005). More studies are now needed to determine the respective role of asymmetrical cell division and delamination during development, skin homeostasis, and pathological conditions such as wound healing.

\section{EMBRYONIC HAIR FOLLICLE MORPHOGENESIS AND THE ADULT HAIR CYCLE}

The development of HFs involves a temporal series of epithelial-mesenchymal interactions (reviewed in Hardy 1992) (Figure 1). First, the dermis signals to the overlying epidermis to make an appendage. In response, the epidermis then transmits a signal to instruct the underlying dermal cells to condense and form the dermal papilla (DP). Another signal is then sent from the DP to promote the proliferation and elaborate differentiation required to form the epidermal appendage.

Dermal papilla (DP), dermal part of the hair follicle, consisting of a small cluster of mesenchymal cells that are densely packed.

The process of HF development has been divided into discrete stages distinguished by their morphological and biochemical differences (Paus et al. 1999). The first morphological sign of HF development is the formation of a hair placode, in which the basal epithelium becomes elongated and invaginates at sites where dermal condensates form. As the developing follicle extends downward and en-wraps the DP, the cells at the base maintain a highly proliferative state. During follicle maturation, these proliferating (matrix) cells begin to differentiate into the inner root sheath (IRS), which is the envelope for the future hair shaft and is marked by the expression of the transcription factor GATA3 and the structural protein trichohyalin (Kaufman et al. 2003, O'Guin et al. 1992). The outer layer of cells becomes the outer root sheath (ORS), which is contiguous with the epidermis and is surrounded externally by the basement membrane. The ORS expresses K5 and K14, similar to the interfollicular epidermis. As the follicle continues to widen, a new inner core of cells appears and begins to express the hair keratin genes of the hair shaft (reviewed in Omary et al. 2004). By postnatal day 8 in mice, follicle downgrowth is complete, and for the next 7 days, matrix cells proliferate and differentiate into the six concentric layers of the IRS and hair shaft (Figure 1).

Inner root sheath (IRS), the inner channel of the hair shaft, which degenerates near the skin surface, thereby enabling the hair shaft to protrude on its own; Hair shaft, the structure composed of terminally differentiated keratinocytes that emerges from the skin surface as 
a hair; Outer root sheath (ORS), the external layer of the hair follicle that maintains contact with the surrounding basement membrane.

At postnatal day 16, proliferation in the matrix ceases, and the lower two-thirds of the HF rapidly degenerates by a process involving apoptosis (catagen stage). An epithelial strand surrounded by the retracting basement membrane draws the DP upward, where in backskin it comes to rest just below the base of this permanent segment of the HF called the bulge. This resting stage is referred to as telogen. In the first hair cycle, telogen lasts approximately one day, but in subsequent cycles, this phase becomes increasingly extended, suggesting the need to reach a biochemical threshold before the next hair cycle can be activated. The new cycle of hair regeneration (anagen) begins with the emergence of a proliferating hair germ, and the progression to form the mature follicle bears a significant resemblance to embryonic folliculogenesis (Muller-Rover et al. 2001) (Figure 2). The periodic cycling of hair growth and degeneration persists throughout the life of the animal and implicates the existence of SCs to fuel the regenerative process.

Catagen, degenerative stage of the hair follicle; Bulge, permanent portion of the hair follicle corresponding to the location of hair follicle stem cells; Telogen, resting stage of the hair follicle when the dermal papilla rests in contact to the base of the permanent portion of the hair follicle (the bulge).

The molecular mechanisms that govern HF morphogenesis and cycling are still poorly understood, but genetic studies in mice reveal the importance of Wnt/ $\beta$-catenin, bone morphogenetic protein (Bmp), sonic hedgehog (Shh), fibroblast growth factor (Fgf), epidermal growth factor receptor (Egf), NFkB, and Notch signaling pathways (reviewed in Millar 2002, Schmidt-Ullrich \& Paus 2005).

\section{STEM CELLS WITHIN THE ADULT SKIN EPITHELIUM}

The adult skin epithelium is composed of molecular building blocks, each of which consists of a pilosebaceous unit (HF and sebaceous gland) and its surrounding interfollicular epidermis (IFE). The IFE contains its own progenitor cells to ensure tissue renewal in the absence of injury, and HFs contain multipotent SCs that are activated at the start of a new hair cycle and upon wounding to provide cells for HF regeneration and repair of the epidermis.

Interfollicular epidermis (IFE), the skin epidermis located between the orifices of the periodically spaced hair follicles.

\section{The Interfollicular Follicular Epidermis}

Evidence for progenitor cells in interfollicular epidermis-The IFE, which generates the lipid barrier of adult skin, constantly renews its surface throughout the entire life of the animal and also undergoes reepithelialization after wound injuries. These renewing and repairing activities of the skin epidermis imply the existence of SCs to ensure these critical functions. Histological analysis has shown that mouse epidermis is organized in stacks of cells with a hexagonal surface area lying on a bed of ten basal cells (Mackenzie 1970; Potten 1974, 1981). This structure was hypothesized to function as an epidermal proliferative unit (EPU) with one putative SC per unit. Researchers tested experimentally the existence of EPUs using lineage-tracing analyses. The first type of lineage tracing was performed by infecting cultured mouse and human keratinocytes with a retrovirus expressing LacZ and grafting these marked keratinocytes onto immunodeficient mice. Alternatively, mice were directly infected with LacZ-virus in skin, following dermabrasion (Ghazizadeh \& Taichman 2001, Kolodka et al. 1998, Mackenzie 1997). Analysis of the chimeric skin revealed the presence of discrete 
columns of blue cells from the basal cells to the most differentiated uppermost layer of cells. These findings demonstrate that EPUs exist in the basal IFE and can be maintained individually as a separate unit for extended periods of time. Such domains can be explained by a mechanism whereby basal cells divide asymmetrically relative to the basement membrane to maintain a proliferative daughter and give rise to a differentiating daughter cell overlying it (Lechler \& Fuchs 2005).

Self-renewal within the epidermis has also been studied using genetic fate mapping, which circumvents the wound response generated in transplantation experiments (Ro \& Rannala 2004). In this case, transgenic mice were engineered to express a mutant form of green fluorescent protein (GFP) that cannot be translated owing to the presence of a stop codon in the EGFP-coding sequence. Subsequently, the mice received topical application of a mutagen to induce mutations that can remove the stop codon and restore expression of a functional GFP protein. These sporadic mutations resulted in patches of GFP-positive cells within the IFE, allowing the visualization of EPU columns. Although elegant, these experiments did not address how many SCs are present in each EPU and where the SCs reside within the unit.

In human skin, the epidermis is thicker and undulates to form deep epidermal ridges (rete ridges) that extend downward in the epidermis and help to anchor the epidermis to the dermis. Used only sparingly, SCs have been proposed to cycle less frequently. The infrequently cycling cells within the IFE are located at the base of these ridges, which is conveniently in a more protected site than elsewhere within the IFE (Lavker \& Sun 1982).

To identify characteristics of IFE SCs, researchers have turned toward in vitro experiments. Cultured human IFE keratinocytes expressing the highest level of $\beta 1$-integrin have the highest proliferative potential in vitro (Jones \& Watt 1993). Other genes have also been shown to be preferentially expressed in $\beta 1$-enriched human keratinocytes, underscoring the biochemical distinctions of this population of basal cells (Legg et al. 2003). As would be expected, the $\beta 1$ bright cells are found in the basal layer, but interestingly, they reside in clusters (Jones et al. 1995). Additionally, the $\beta 1$-bright cells do seem to reside at the base of the deepest epidermal ridges of palmoplantar skin, consistent with the location of slow-cycling SCs observed by Lavker \& Sun (1982). Elsewhere, however, the $\beta 1$-bright clusters reside outside these zones, in a seemingly more compromised position for SCs. Hence, the extent to which $\beta 1$-integrin levels define the distinguishing features of IFE SCs must await further studies. In this effort, additional markers are needed to enrich the purification and analyses of IFE cells with high proliferative potential. Such markers should also help in defining the location and the number of IFE SCs within their functional EPU columns and in discerning the extent to which less frequent cycling is a measure of stemness within the IFE population. A final issue to be resolved is the extent to which cells with high proliferative potential in the basal layer of the IFE are able to contribute to other cell lineages, i.e., those of the sebaceous gland and HF.

Interfollicular epidermis stem cell self-renewal in vitro: Clinical potential and clonogenicity studies-In the mid-1970s, Rheinwald \& Green (1975) defined culture conditions allowing the growth of human IFE SCs in vitro. This seminal discovery allowed the propagation of keratinocytes from severely burned patients and their subsequent grafting as sheets of autologous cultured cells that were functional in reepithelializing the damaged skin (Gallico et al. 1984, O'Connor et al. 1981, Pellegrini et al. 1999, Ronfard et al. 2000). In the past 25 years, this technology has saved many lives. Although the patient's repaired skin epithelium does not regenerate sweat glands or HFs, it does have a normal epidermis, which can undergo wound repair.

When plated at low cell density, cultured human keratinocytes can form three types of colonies: (a) highly proliferative colonies (holoclones) of small round cells that present an 
undifferentiated morphology and that can be passaged long-term, $(b)$ aborted colonies (paraclones) displaying large flat morphology typical of terminally differentiated cells, and (c) relatively small heterogeneous colonies (meroclones) of limited proliferative potential that become senescent after a few rounds of passaging (Barrandon \& Green 1987). Although the term holoclone refers only to the proliferative capacity of the colony, the progeny of a single epidermal holoclone in vitro can re-form a functional and renewable epidermis in vivo (Rochat et al. 1994). This implies that at least some cells within holoclones possess the fundamental characteristics of a SC in that they can self-renew and differentiate into a functional tissue. By contrast, meroclones have been likened to so-called transit-amplifying cells, i.e., cells with a limited number of cell divisions before they commit to terminally differentiate. Although the precise physiological relevance of these cultured populations of cells remains to be determined, the in vitro description of their clonal properties has served as a useful foundation for the analyses of SCs in vivo.

\section{The Bulge Stem Cell Niche}

In the hair follicle, SCs reside in a discrete microenvironment called the bulge, located at the base of the part of the follicle that is established during morphogenesis but does not degenerate during the hair cycle. Bulge SCs are more quiescent than other cells within the follicle.

However, during the hair cycle, bulge SCs are stimulated to exit the SC niche, proliferate, and differentiate to form the various cell types of mature HFs. In addition, to provide cells during $\mathrm{HF}$ regeneration, the bulge $\mathrm{SC}$ is a reservoir of multipotent SCs that can be recruited during wound healing to help the repair of the epidermis. We summarize here the recent progress in the functional and molecular characterization of bulge SCs.

\section{Label-retaining cells and their movements during the hair cycle and in response} to injury-For many years, it was thought that the SCs that regenerate HFs during the hair cycle are the highly proliferative matrix cells (Kligman 1959). This model was later challenged when Montagna \& Chase (1956) observed that X-ray irradiation kills the matrix cells, but hairs can still re-form from cells within the ORS. The ability of the upper ORS to act in concert with the DP to make HFs was further substantiated by dissection and transplantation experiments (Jahoda et al. 1984; Oliver 1966, 1967).

Mathematical modeling has supported the notion that SCs may be used sparingly and hence divide less frequently than their progeny (Potten et al. 1982). This notion was bolstered by administering repeated doses of marked nucleotide analogs such as BrdU or 3[H]-thymidine to label the S-phase cycling cells of the skin (pulse period) and then following the fate of the incorporated label over time (chase period). The differentiating cells are sloughed from the skin surface, and the more proliferative cells dilute their label as they divide, marking the least proliferative cells as label-retaining cells (LRCs) (Bickenbach 1981).

To locate HF LRCs, Lavker and colleagues (Cotsarelis et al. 1990) administrated BrdU for a week in newborn mice and then analyzed label retention in the skin after four weeks of chase. The majority of LRCs in the skin resided in a specialized region at the base of the permanent segment of the HF. Known as the bulge, this region was described more than a century ago by histologists (Stohr 1903). Within the ORS, the bulge resides just below the sebaceous gland at a site where the arrector pili muscle attaches to the follicle (Figure 2). Although its origins are likely to be traced to the early stages of HF embryogenesis, the bulge acquires its distinctive appearance when the first postnatal hair germ emerges before the prior club hair has been shed (Figure 2). During the first telogen phase, a single layer of quiescent cells surround the old club hair; as the new hair cycle initiates, the bulge acquires a second layer of cells (Blanpain et al. 2004). 
Although generally quiescent, bulge cells can be prompted to proliferate artificially in response to mitogenic stimuli such as phorbol esters (TPA) or naturally at the start of each hair cycle. In an elegant double-label study to demonstrate a precursor-product relation, Taylor et al. (2000) showed that when BrdU-labeled LRCs in the bulge are exposed to a brief pulse of a second nucleotide label, they incorporate $3[\mathrm{H}]$-thymidine as they exit and proliferate to develop the new hair germ. To directly determine whether the bulge region contains SCs, Barrandon and coworkers (Kobayashi et al. 1993) dissected rat and human HFs and assessed the growth potential of different HF segments in vitro. In rat-whisker follicles, 95\% of the derived holoclones came from cells of the bulge segments, whereas less than $5 \%$ of the growing colonies could be derived from the matrix region. In adult human skin, keratinocytes with high proliferative potential were also found within bulge segments, but the zone of clonogenic cells was broader, extending from the bulge to the lower ORS (Rochat et al. 1994). In this regard, in adult human skin, the bulge is notably a less distinctive structure than it is in rodents.

Anagen, growing stage of the hair follicle.

Early studies involving reepithelialization during wound repair led researchers to posit that HFs may have the capacity to regenerate epidermis upon injury (Argyris 1976). To evaluate whether bulge LRCs have this capacity, Taylor et al. (2000) extended their double-labeling techniques to wound-healing experiments. Indeed, following a wound, BrdU-labeled cells derived from the bulge could be found proliferating within the epidermis near the HF orifice (infundibulum).

Fuchs and coworkers (Tumbar et al. 2004) recently adapted the nucleotide pulse-chase experiments to the protein level by engineering mice expressing a tetracycline-regulated histone H2B-GFP protein in their skin epithelium. In the absence of tetracycline, all the skin epithelial nuclei were green with H2B-GFP expression, but when tetracycline was administered, the gene was shut off, and after four weeks, only the bulge cells still labeled brightly with H2B-GFP protein (Figure 3a). Upon wounding, H2B-GFP-positive cells were detected in the epidermis and infundibulum, confirming the ability of bulge LRCs to reepithelialize the epidermis in response to injury (Tumbar et al. 2004). Upon activation of the hair cycle, the emerging hair germ displayed H2B-GFP-positive cells with much weaker fluorescence than the bulge, suggesting that they were derived from the bulge LRCs. These findings support the studies of Barrandon, demonstrating the ability of bulge cells to regenerate the HF during the normal hair cycle.

Several lines of evidence suggest that there is a continuous flux of bulge cells throughout the growing stage of the hair cycle. During the anagen phase of the backskin hair cycle, Tumbar et al. (2004) detected a trail of H2B-GFP-positive cells along the lower ORS. Although these cells were less bright than their bulge LRC counterparts, the results were intriguing in light of rat-whisker bulge transplantation and clonogenic experiments performed by Barrandon and colleagues (Oshima et al. 2001). Based on these seminal studies, researchers proposed that SCs migrate from the bulge along the basal layer of the ORS to the matrix, where they proliferate and differentiate to produce the hair and IRS. Although the hair cycle of whisker follicles differs from those in the backskin in that the growing stage is longer and follicles transit from midcatagen directly to anagen, a common theme for SC movement and activation likely applies for HFs, irrespective of whether they are whisker or pelage follicles.

Methods to isolate and purify bulge label-retaining cells: Evidence for selfrenewal of stem cells-In the past ten years, researchers have made considerable strides in isolating and purifying cells from the HF bulge. Given the complexity of the skin, purification of bulge cells using flow cytometry (FACS) has focused on isolating bulge cells in the simpler, telogen-phase follicles, where the quiescent bulge marks the base. Kaur and colleagues ( $\mathrm{Li}$ et 
al. 1998) have employed conjugated antibodies against $\alpha 6$-integrin and anti-CD71 (antitransferin $\mathrm{Ab}$ or 10G7) to show that $\alpha 6$-bright, $\mathrm{CD} 71$-dim cells from skin possess similar colony-forming efficiency but higher long-term growth potential than the rest of the population. Bulge LRCs share this expression pattern and are enriched in the a6-bright, CD71-dim population by approximately twofold (Tani et al. 2000). Other markers such as S100A4 and S100A6 proteins (Ito \& Kizawa 2001), K19 (Michel et al. 1996), K15 (Lyle et al. 1998), and CD34 (Trempus et al. 2003) have also been reported to exhibit preferential expression in the bulge. Although most of these antibodies have not proven useful for isolating living bulge cells by FACS, CD34 is an exception. CD34-positive cells are enriched tenfold for LRCs, and they form larger colonies than unfractionated epidermis (Trempus et al. 2003).

When transgenic expression of a basal epidermal marker (K14-GFP) is used in conjunction with antibodies against $\alpha 6$-integrin and CD34, purification of bulge cells is enhanced substantially (Blanpain et al. 2004). On the basis of differential $\alpha 6$ expression, the CD34/K14GFP-positive cells from the inner and outer layers of the mature bulge can also be fractionated (Figure 3b). Bulge cells have also been purified from K15-GFP-transgenic skin in conjunction with $\alpha 6$-integrin antibodies (Morris et al. 2004), and when tetracycline-regulatable H2B-GFP mice are employed for bulge purification, a 70-fold enrichment of bulge LRCs can be achieved over unfractionated skin epithelial cells (Tumbar et al. 2004). In all three of these methods for obtaining bulge cells with high purity, bulge cells form large colonies that can be passaged in vitro (Morris et al. 2004, Tumbar et al. 2004). This is true for both the inner and the outer layer of the bulge (Blanpain et al. 2004) (Figure 3). Clonogenicity studies further demonstrate that a large colony derived from a single bulge cell can give rise to multiple large colonies upon passaging, implying the occurrence of SC self-renewal in vitro (Blanpain et al. 2004, Claudinot et al. 2005).

Multipotency of bulge stem cells-The two major properties of SCs are their abilities to self-renew and to differentiate along multiple lineages. To address the differentiation potential of bulge SCs, researchers have used a variety of methods, including $(a)$ transplantation studies of microdissected HF segments, $(b)$ direct transplantation and clonal analysis of isolated bulge cells, and $(c)$ genetic fate mapping in mice.

In pioneering studies, Oshima et al. (2001) generated chimeric rodent-whisker follicles by removing the unlabeled bulge of a wild-type vibrissae follicle, replacing it with a lacZexpressing bulge microdissected from a transgenic mouse-whisker follicle and transplanting the chimeric follicle into the kidney capsule and/or embryonic backskin from immunodeficient mice. Thirty days after transplantation, lacZ-marked cells were detected in the epidermis, sebaceous gland, and HFs (Oshima et al. 2001). Morris et al. (2004) have obtained similar results using $10^{5}$-FACS-isolated K15-GFP-tagged bulge cells transplanted into immunodeficient mice.

In the experiments of Barrandon and coworkers, temporal analysis of anagen-phase chimeric whisker follicles revealed a downward flux of lacZ-positive cells originating from the transplanted bulge, migrating to the matrix and subsequently differentiating into one of the six concentric rings of IRS and hair shaft lineages. Although at reduced frequency, cells residing in the lower HF were also able to differentiate into multiple skin cell lineages (Oshima et al. 2001). These findings support the view that SCs migrate from the bulge to the base of the follicle before they differentiate and lose their potential. As outlined above, it still remains to be resolved as to whether a continuous downward flux of bulge cells occurs only in whiskers or human HFs, in which the hair cycle displays a prolonged anagen phase, or whether it is a feature common to all HFs. 
The studies above beautifully underscore the potential of cells within the bulge region to differentiate along the three different lineages afforded to the skin keratinocyte. However, they do not address whether the bulge consists of multiple types of unipotent progenitors, each of which are able to differentiate along one lineage, or whether individual bulge cells possess multipotency, the ability to differentiate along any of the three lineages. To date, technical hurdles have precluded testing for multipotency using in vivo clonal analyses. However, in the past few years, researchers have employed clonal analyses in vitro to demonstrate definitively the multipotency of bulge cells when passaged in vitro (Blanpain et al. 2004, Claudinot et al. 2005).

In the first study, Fuchs and coworkers (Blanpain et al. 2004) placed isolated K14-GFP-tagged bulge cells in culture to obtain individual holoclones. After short-term expansion, the descendents from a single bulge cell were then transplanted onto the backs of nude mice. The progeny of single bulge-derived holoclones each gave rise to GFP-positive HFs, IFE, sebaceous gland, and even bulge SCs (Blanpain et al. 2004). Similar results were obtained by Barrandon and coworkers (Claudinot et al. 2005), who were able to generate thousands of HFs from the progeny of a single cultivated rat-whisker SC. These experiments provide compelling evidence in support of the notion that cells within the adult follicle bulge possessing the classical criteria of bona fide multipotent SCs. That the inner bulge layer also has this capacity further suggests that even when bulge cells detach from the basal lamina and appear to undergo early commitment to the HF lineage, the process is reversible, at least after in vitro culture (Blanpain et al. 2004).

Unipotent progenitor ensuring renewal of the interfollicular epidermis-Under normal circumstances, the bulge acts as a reservoir of follicle SCs, and only in response to injury has it been shown to mobilize and function as a multipotent SC reservoir. Whether there are other multipotent SCs in adult skin remains to be demonstrated. However, there is substantial evidence that unipotent SCs exist in other locations in the skin. Fate-mapping experiments using a Cre recombinase that permanently marks bulge cells reveal that under physiological conditions, the IFE contains only rare patches of $\beta$-galactosidase-positive cells derived from bulge cells. These data reinforce the notion postulated above on the basis of EPU columns: Normal IFE homeostasis is controlled by the presence of unipotent progenitors that reside within the IFE (Ito et al. 2005, Levy et al. 2005, Morris et al. 2004). That bulge SCs are not necessary for epidermal homeostasis is perhaps best exemplified by the fact that palmoplantar skin lacks HFs altogether, as do a number of genetic hair disorders, yet epidermal homeostasis and wound repair can still take place (Montagna et al. 1954).

Microarray analysis of bulge stem cells-To determine which genes and signaling pathways operate within the bulge SCs, researchers have performed transcriptional profiling on isolated telogen-phase bulge cells (Blanpain et al. 2004, Morris et al. 2004, Tumbar et al. 2004). In most cases, these profiles have been compared with those of basal epidermal cells, which have proliferative capacity but are thought to contain few if any multipotent SCs. Notably, most of the transcripts upregulated in either the Tumbar or Morris arrays were upregulated in the Blanpain array, which encompassed a considerably larger gene set compared with the two earlier studies. Blanpain et al. (2004) list 56 transcripts that scored as upregulated in bulge cells irrespective of the isolation method, hair cycle stage, or attachment to the basal lamina and that can be viewed as a molecular signature of bulge cells.

Interestingly, $14 \%$ of genes found to be upregulated in other types of SCs (hematopoeitic SC, neuronal SC, and embryonic SC) (Ivanova et al. 2002, Ramalho-Santos et al. 2002) were also found to be a part of the bulge signature (Blanpain et al. 2004), suggesting that certain genes within this list are likely involved in the unique properties common to many if not all SCs. Related to this issue are the important similarities recently uncovered between these mouse 
bulge SC profiles and those of human bulge SCs (Ohyama et al. 2006). Although some differences were noted (CD34, for example, extends to the lower ORS in human follicles), this similarity bodes well for future clinical studies aimed at improving the potential of skin SCs for therapeutic purposes.

The bulge signature now provides a constellation of markers that should enable researchers to examine the extent to which bulge cells retain their program of gene expression as they respond to natural stimuli, e.g., during the hair cycle and upon injury, and as they exit the niche to migrate and/or differentiate along particular lineages. The list should also be useful in examining how the bulge cells change their properties in response to various genetic manipulations. Through such future examinations, scientists should begin to uncover the extent to which the bulge signature is a reflection of the quiescence of these SCs and identify the subset of these genes involved in self-renewal and in suppression of lineage determination irrespective of whether a skin SC is quiescent or proliferative.

Although these studies are in their infancy, a few important lessons are already emerging. One intriguing aspect of the transcriptional profiling conducted on the bulge to date is the high degree to which the bulge signature is maintained in both anagen and telogen stages of the hair cycle and in basal and suprabasal bulge layers (Blanpain et al. 2004). These findings underscore the powerful influence that the microenvironment of the bulge niche has on its residents. In turn, for a bulge $\mathrm{SC}$ to become mobilized and exit the niche, this dominance must be overcome.

Although researchers are conducting additional experiments to dissect the molecular significance of the bulge signature, it is tempting to speculate on the roles of various transcripts that are either up- or downregulated preferentially in the bulge. To this end, a number of bulge signature genes encode cell adhesion, cytoskeleton, and ECM components. We posit that these genes may reflect the specialized microenvironment that must be suitable not only for maintaining their SC characteristics within the niche, but also for allowing bulge SCs to exit their niche and migrate during wound repair and/or in hair regrowth.

The bulge signature also provides a battery of candidate genes likely to play a role in SC quiescence. Most notable are the many upregulated genes encoding cell-cycle inhibitory factors, such as $C d k n 1 b$ (p27), $C d k n 1 c$ (p57), and $C d k n 2 b$ (p15), and the numerous downregulated genes encoding cell-cycle-promoting factors, such as Ki67, proliferating cell nuclear antigen, cyclins (Cyclin D1, D2, A2, B1) and cyclin-dependent kinases, and celldivision-cycle-related genes ( $C d c 2 a, 2 b, 6,7,25 c)$ (Blanpain et al. 2004, Morris et al. 2004, Tumbar et al. 2004). Although the cell cycle is typically thought to be regulated largely at the posttranslational level, the transcriptional regulation of these cell-cycle genes suggests that the quiescent nature of the bulge is governed by unique operational control mechanisms.

Finally, another interesting set of bulge signature genes contains those that are likely involved in maintaining the SCs in an undifferentiated, growth-inhibited state. Of these genes, it is particularly interesting that many components of the Wnt/ $\beta$-catenin signaling pathway (Tcf3; $T c f 4 ; D k k-3 ; s F R P 1 ; F z d 2,3,7 ; D a b 2 ; C t b p 2)$ and the TGF- $\beta /$ Bmp signaling pathways (Ltbp 1, 2, 3; Tgf- $\beta 2$; Gremlin) are upregulated in the bulge. These pathways are discussed individually in the sections below.

\section{SIGNALING AND STEM CELL FATE SPECIFICATION IN THE SKIN}

\section{Wnt/ $\beta$-Catenin Signaling}

The Wnt/ $\beta$-catenin signaling pathway is conserved throughout the eukaryotic kingdom, where it controls a myriad of different cellular decisions during embryonic and postnatal development 
(Figure 4a). Wnt deregulation leads to an imbalance of proliferation and differentiation, often resulting in cancers (Reya et al. 2001).

Wnts compose a large family of cysteine-rich secreted glycoproteins that activate Frizzled receptors, which in turn stimulate a cascade of events culminating in the stabilization and accumulation of cytoplasmic $\beta$-catenin. Normally, cellular $\beta$-catenin is complexed with Ecadherin and $\alpha$-catenin at adherens junctions, and free cytoplasmic $\beta$-catenin is degraded by the proteasome. Upon Wnt signaling, excess $\beta$-catenin is no longer degraded, and it is free to complex with and activate members of the Tcf/Lef1 family of transcription factors (Logan \& Nusse 2004) (Figure 5).

In the skin, Wnt and $\beta$-catenin play diverse roles in HF morphogenesis, SC maintenance and/ or activation, hair shaft differentiation, and also pilomatricoma tumor formation in mice and humans (Alonso \& Fuchs 2003). Activation of Wnt/ $\beta$-catenin signaling is critical during the first stage of HF morphogenesis, as evidenced by the absence of placode formation on conditional ablation of $\beta$-catenin (Huelsken et al. 2001) or constitutive expression of a soluble Wnt inhibitor (Dkkl) (Andl et al. 2002). Although the source and identity of the putative Wnt signal required to induce placode formation remain elusive, it may be the first dermal signal to instruct epidermal cells to make hair. Consistent with this notion is the activation in both the placode and the postnatal hair germ of a Wnt reporter gene driving lacZ under the control of an enhancer composed of multimerized binding sites for the Lef1/Tcf DNA-binding proteins that interact with and are activated by association with $\beta$-catenin (DasGupta \& Fuchs 1999, Reya \& Clevers 2005) (Figure 4b). Nuclear $\beta$-catenin and Lef1 expression are also seen in embryonic placodes and postnatal hair germs at this time (Merrill et al. 2004, van Genderen et al. 1994, Zhou et al. 1995). Noggin, a soluble inhibitor of Bmps, is expressed by the mesenchymal condensate and is required in the early stage of HF morphogenesis and cycling. It appears to act at least in part by promoting expression of Lef1 (Botchkarev et al. 2001, Jamora et al. 2003).

Transgenic mouse studies support a role for Wnt signaling in the specification of HF development. Mice expressing a constitutively stabilized $\beta$-catenin $(\Delta>N \beta$-catenin $)$ display de novo HFs (Gat et al. 1998) (Figure 4c), whereas mice lacking Lef1 (van Genderen et al. 1994) or $\beta$-catenin (Huelsken et al. 2001) or overexpressing the Wnt inhibitor Dkk1 exhibit a paucity of follicles (Andl et al. 2002).

Postnatally, the strongest Wnt signal is associated with the terminally differentiating cortical cells of the hair shaft (DasGupta \& Fuchs 1999) (Figure 4b). The hair keratin genes possess Lef1/Tcf DNA-binding domains and are bona fide targets for Wnt-mediated gene expression (Merrill et al. 2001, Zhou et al. 1995). This lineage of the matrix cells appears to be particularly singled out for robust Wnt signaling, as K14- $\Delta N \beta$-catenin transgenic mice develop pilomatricomas, which are pure tumor masses of cortical cells (Gat et al. 1998). Similarly, the majority of human pilomatricomas possess N-terminal stabilizing mutations in the coding sequence of the $\beta$-catenin gene (Chan et al. 1999, Xia et al. 2006).

In contrast to the cortical cells, the bulge is largely silent for Wnt reporter activity (DasGupta \& Fuchs 1999). Microarray data suggest that the bulge is normally in a Wnt-inhibited environment, showing an upregulation of genes encoding putative Wnt-inhibitory factors (sFRP1, Dkk3, Wif) and a downregulation of genes encoding Wnt-promoting factors in the bulge (Wnt3, Wnt3a). However, bulge SCs express a number of frizzled surface receptors $(F z 2,3$, and 7$)$ to enable them to receive Wnt signals as well as Wnt-signaling-related transcription factors ( $T c f 3, T c f 4, T l e 1, C t b p 2)$ to enable them to transmit a Wnt signal (see Tumbar et al. 2004). In this regard, Tcf3 is intriguing, as it has been shown to act as a repressor in the absence of Wnt signaling (Merrill et al. 2001, 2004). Taken together, these findings 
suggest that bulge SCs are in a quiescent, Wnt-inhibited state and that Wnt signaling plays a key role in driving these cells along at least one hair differentiation lineage (Figure 4d).

Several studies suggest that the role of Wnt signaling in the postnatal HF may be even broader. The involvement of Wnts in HF morphogenesis suggests that Wnt signaling may be important for activating bulge SCs. Consistent with this notion is the presence of a few Wnt-reporterdriven, LacZ-positive bulge cells at the beginning of the hair cycle (DasGupta \& Fuchs 1999). The number of activated bulge cells can be considerably enhanced by breeding the Wntreporter mice on the background of K14- $\Delta N \beta$-catenin mice; at most stages of the hair cycle, however, the bulge remains silent for Wnt-reporter activity (DasGupta \& Fuchs 1999, Merrill et al. 2001).

By inducing the expression of stabilized $\beta$-catenin in telogen-phase follicles, several groups have observed precocious activation of hair regeneration (Lo Celso et al. 2004, Lowry et al. 2005, Van Mater et al. 2003), in a fashion reminiscent of the de novo follicle morphogenesis that occurs in the IFE (Gat et al. 1998). Despite the premature transition from telogen to anagen, the K14- $\Delta N \beta$-catenin bulge reenters its relatively quiescent state once the follicle has grown downward (Lowry et al. 2005). These findings imply that some additional factor(s) is required in addition to elevated Wnt signaling to change the status of Lef1/Tcf-regulated genes (including TopGal) and activate bulge SCs. It is tempting to speculate that this signal emanates from the DP, given the close proximity of the DP to the bulge prior to the start of the hair cycle. One candidate may be the Bmp-inhibitor Noggin, produced by the DP and shown to be required for Lef1 expression in the embryonic hair placode and in the matrix cells as well (Andl et al. 2004, Botchkarev et al. 1999, Jamora et al. 2003, Kobielak et al. 2003). Fgf7 and Fgf10 are additional candidates known to be expressed in the bulge and to have an impact on follicle morphogenesis (Guo et al. 1993, Petiot et al. 2003).

Despite the continuous presence of an elevated level of stabilized $\beta$-catenin, the size of the SC niche does not change over time (Lowry et al. 2005). This means that if elevated $\beta$-catenin promote the self-renewal of bulge SCs, it must be accompanied by an increase in the rate at which SCs exit the niche. Two factors consistent with this notion are that the rate of BrdUlabel retention is reduced and the level of BrdU-label incorporation is enhanced in the K14$\Delta \mathrm{N} \beta$-catenin bulge. That said, this increased proliferation appears to be manifested in precocious SC activation, as it was not accompanied by a noticeable increase in the length of the hair or the cellularity of HFs.

To understand how $\beta$-catenin elevation can promote SC activation in the bulge, Lowry et al. (2005) conducted microarray analyses on telogen- or anagen-phase SCs isolated from $\Delta N \beta$ catenin or wild-type follicles. Intriguingly, some telogen-phase bulge genes affected by $\Delta N \beta$ catenin were similarly affected in the normal anagen-phase bulge, suggesting the transgeneinduced changes may reflect natural changes that occur in the telogen-to-anagen transition of the hair cycle. Although further studies are needed to assess the extent to which this is the case, genes that surfaced in these arrays and that may play a role in Wnt-mediated bulge SC activation include Cyclin D2 (Ccnd2), Sox4, and Biglycan (Lowry et al. 2005). Another protein upregulated in the early anagen bulge appears to be the transcriptional corepressor Hairless, which has been proposed to function by blocking the expression of the soluble Wnt inhibitor Wise, which in turn may lead to Wnt-mediated SC activation (Beaudoin et al. 2005). An additional interesting twist is the recent study reporting that $S h$ is a downstream target of Wntmediated activation of follicle SCs (Silva-Vargas et al. 2005). Shh is particularly intriguing as a Wnt candidate, as it would integrate these two key signaling pathways essential for HF morphogenesis. That said, on the basis of the differential expression of direct Wnt target genes and $S h h$, it seems unlikely that $S h h$ is a direct target for Wnt signaling in bulge cells (Lowry et al. 2005). We discuss the Shh pathway in greater depth below. 
In summary, these findings delineate sequential roles for Wnt signaling in temporally regulating follicle SC lineages, perhaps in a fashion that depends on the level of the signal: (a) $\beta$-catenin stabilization promotes bulge SC activation, proliferation, and induction of follicle regeneration; (b) $\beta$-catenin stabilization promotes the specification of matrix cells to terminally differentiate along the hair (cortical) cell lineage; (c) $\beta$-catenin stabilization promotes de novo HF morphogenesis; and $(d)$ constitutively active $\beta$-catenin expression results in pilomatricoma hair tumors. The particular fate selected by a follicle cell appears to depend on a constellation of intrinsic and extrinsic factors, which together influence the status of Tcf/Lef1-regulated genes. At the Wnt-inhibited end of the spectrum is SC quiescence, and at the constitutive Wnt end is tumorigenesis (Figure 4d).

\section{Shh Signaling}

Similar to Wnt/ $\beta$-catenin, Shh is an ancient signaling pathway involved in cell fate specification and proliferation during animal development (Taipale \& Beachy 2001). The Shh transmembrane receptor is Patched (Ptch), which is active in the absence of Shh (Figure 5a). Ptch functions by inhibiting Smoothened (Smo), which is essential to transduce the Shh signal through the Gli family of transcription factors to induce target gene expression. Ptch itself is a Shh target gene, resulting in the localized sequestration of Shh and the restriction of longrange signaling (Casali \& Struhl 2004).

Given the prominence of the Shh pathway in development and proliferation, it is not surprising to find that when deregulated, this pathway leads to tumorigenesis. Rubin et al. (2005) illuminated its importance in skin with the finding that Ptchl gene mutations cause basal cell nevus syndrome, a hereditary predisposition to basal cell carcinomas (BCCs), the most common type of skin cancer in humans. In the skin, Ptch acts as a tumor suppressor gene, as loss of heterozygosity at the Ptch locus (chromosome 9q22.3) has been observed in sporadic BCC and BCCs isolated from patients with basal cell nevus syndrome (Gailani et al. 1996, Hahn et al. 1996, Johnson et al. 1996, Unden et al. 1996). Activating mutations in Smo have also been detected in sporadic BCCs (Xie et al. 1998), and overexpression of Shh, Smo, Gli1, or Gli2 leads to BCCs in mice (Dahmane et al. 1997, Grachtchouk et al. 2000, 2003; Hutchin et al. 2005; Oro et al. 1997; Xie et al. 1998). Recently, Vidal et al. (2005) demonstrated that an HMG transcription box factor, Sox9, is also upregulated in BCC, and epistasis experiments suggest that Sox9 is downstream of the Shh signaling pathway in skin.

BCCs are thought to be derived from HFs, and consistent with this notion, Shh is expressed in the hair placodes of embryonic skin (St-Jacques et al. 1998) (Figure 5b). As revealed by Ptch expression, Shh is likely to signal in both the epithelial hair germ and its underlying mesenchymal condensate, suggesting its potential role in the epithelial-mesenchymal cross talk essential for follicle formation (Oro \& Higgins 2003, Oro et al. 1997). Loss-of-function mutations in $S h h$ are still permissive for hair germ formation, placing $S h h$ genetically downstream of Wnt and Noggin signaling (Figure 5c). However, placodes fail to develop further, thus positioning Shh upstream from the proliferative cascade essential for HF morphogenesis (Chiang et al. 1999, St-Jacques et al. 1998, Wang et al. 2000). Mice deficient in Gli2 present a phenotype similar to $S h$-null mice, suggesting that Shh acts mainly through Gli2 in HF (Mill et al. 2003).

Shh signaling is also important for follicle regeneration during the adult hair cycle. Although not expressed in the bulge, Shh is expressed in the matrix and in the developing germ, where it becomes polarized to one side during anagen progression (Figure 5b). The mechanisms underlying this exquisite restriction in expression are not understood, but Shh signaling is likely to span the matrix, as evidenced by Ptch expression (Gat et al. 1998, Oro \& Higgins 2003). As would be predicted from the relative roles of Shh and Wnt signaling in embryonic skin, antiShh antibodies delivered to postnatal follicles block anagen progression (Wang et al. 2000), 
and similarly the Shh inhibitor cyclopamine blocks hair regeneration (Silva-Vargas et al. 2005). Conversely, Shh or small-molecule Shh agonists accelerate the progression from telogen to anagen (Paladini et al. 2005, Sato et al. 1999).

Whereas Shh plays a role in matrix cell proliferation in the hair cycle, Indian hedgehog (Ihh) is expressed in the sebaceous gland. Additionally, both human and mouse sebaceous tumors overexpress $I h h$ but not $S h h$. In normal sebaceous glands, Ihh is expressed in differentiating sebocytes, and nuclear Gli1 is present in sebocyte progenitors (Niemann et al. 2003). In vitro inhibition of hedgehog signaling inhibits growth and stimulates differentiation of sebocytes, suggesting a paracrine mechanism by which Ihh secreted by differentiated sebocytes stimulates proliferation of sebocyte precursors (Niemann et al. 2003). Transgenic overexpression of the other members of Shh family shows that Desert hedgehog is a functional homolog to Shh in the skin (Adolphe et al. 2004).

\section{Bone Morphogenetic Protein Signaling}

Bmps are secreted proteins that activate signal transduction by binding to a transmembrane receptor complex composed of Bmpr1a and Bmpr1b receptors. Upon ligand binding, Bmpr1b phosphorylates the cytoplasmic tail of Bmpr1a, which in turns phosphorylates the R-Smad DNA-binding protein (Smad 1, 5, and 8), which in turn complexes with one of its partner Smads (typically Smad 4) to translocate to the nucleus and mediate target gene expression (Shi \& Massague 2003) (Figure 6a).

Bmpr1a is expressed throughout most of the developing skin epithelium. The pattern of Bmp expression is particularly elaborate in the HF. In early skin development, Bmp2 is expressed in the placode epithelium, whereas Bmp4 is expressed by the underlying mesenchyme (Kratochwil et al. 1996; Lyons et al. 1989, 1990; Wilson et al. 1999). In adult HFs, Bmps also appear to function in epithelial-mesenchymal interactions. In the DP, Bmp4, -6, and -7 are expressed (Kratochwil et al. 1996; Lyons et al. 1989, 1990; Rendl et al. 2005; Wilson et al. 1999), although Bmp6 may also function in bulge SC quiescence and/or maintenance (Blanpain et al. 2004). In addition, Bmps are differentially expressed in the various lineages of the HF, with Bmp7 and -8 in the IRS and Bmp2 and -4 in the hair shaft precursors.

The role for Bmp signaling in skin development begins in the neuroepithelium, when Bmp signaling specifies uncommitted ectodermal cells to become epidermis (Nikaido et al. 1999). Once the embryonic skin SC progenitor cells have been specified, the next crossroads for signaling appears to be at the juncture of hair placode formation. In a process bearing a certain resemblance to the formation of the neural tube, placode formation is dependent on Noggin, a soluble inhibitor of Bmp signaling (Botchkarev et al. 1999, Jamora et al. 2003). Conditional ablation of the Bmprla gene also results in the accumulation of large masses of undifferentiated, Lef1-expressing, placode-like cells, further emphasizing a role for Bmp inhibition in the early stages of HF morphogenesis (Andl et al. 2004, Kobielak et al. 2003).

The conditional targeting of the Bmprla gene also revealed a positive role for Bmp signaling in the differentiation of matrix cells into IRS and hair shaft lineages (Andl et al. 2004, Kobielak et al. 2003, Ming Kwan et al. 2004, Yuhki et al. 2004). Several markers of matrix cell differentiation (FoxN1/nude, Hoxc13, Msx2, and GATA3) were strongly reduced or absent following the ablation of Bmprla. Notably and in striking contrast, Shh and Lef1 expression was expanded, as is also seen in transgenic mice expressing Noggin under the control of the Msx 2 promoter (Kulessa et al. 2000). Nuclear $\beta$-catenin was also decreased in the Bmpr1adeficient matrix cells, demonstrating that Bmp signaling lies upstream of $\beta$-catenin signaling during matrix cell differentiation. These findings strengthen the view that the inhibition of Bmp signaling is required for $\mathrm{SC}$ activation toward the $\mathrm{HF}$ cell fate, whereas Bmp signaling is 
required for the differentiation of activated SCs to adopt one or more of the six different lineages that compose the mature HF (Kobielak et al. 2003).

Several other lines of evidence suggest that the inhibition of Bmp signaling promotes SC activation. At the conclusion of the normal hair cycle, proliferation ceases and the HF enters the destructive phase (catagen). By contrast, Bmprla-null ORS continues to proliferate and grow downward, leading to an accumulation of matrix cells and the formation of follicular tumors (Andl et al. 2004, Ming Kwan et al. 2004). Conversely, treatment of cultivated bulge SCs with BMP6 inhibits their proliferation and leads to a transient withdrawal from the cell cycle (Blanpain et al. 2004, Botchkarev et al. 1999).

\section{Notch Signaling}

Similar to other major signaling pathways in skin, Notch signaling is involved in a variety of cell fate decisions across the animal kingdom. Transmembrane Notch receptors (Notch1-4 in mammals) bind transmembrane ligands, either Jaggeds (2) or deltas (3). Upon ligand engagement, membrane Notch receptors are sequentially cleaved, first by a metalloproteinase and then by $\gamma$-secretase, which releases the active Notch intracellular domain (NICD), freeing it to translocate to the nucleus and associate with the DNA-binding protein RBP-Jк. Upon NICD binding, RBP-J $\kappa$ is converted from a transcriptional repressor to an activator, leading to the induction of downstream Notch target genes (Artavanis-Tsakonas et al. 1999) (Figure 7a).

Multiple components of the Notch signaling pathway are expressed in embryonic and adult epidermis. During the early stage of epidermal stratification, Notch1 is expressed and active in the basal and suprabasal cells of the epidermis and sebaceous glands (Okuyama et al. 2004, Rangarajan et al. 2001) (Figure 7b). In the latter stages of epidermal stratification, Notch1 activity decreases in the basal layer and becomes more restricted to the spinous layer (K1positive cells) (Okuyama et al. 2004). Loss of Notch1 function results in a defect of IFE differentiation (Rangarajan et al. 2001).

In the HF, Notch1-3 are expressed in proliferative matrix cells and in differentiating HF cells (Kopan \& Weintraub 1993, Pan et al. 2004) (Figure 7b). When both Notch 1 and Notch2 or PS1 and PS2 genes involved in Notch processing are conditionally ablated in the matrix, HFs are quantitatively lost and epidermal cysts arise, underscoring the role for Notch signaling in follicle maturation and differentiation (Pan et al. 2004). The consequences of Notchl deletion are most directly deleterious to the sebaceous glands, which are reduced in the single conditional knockout animals; in the absence of both Notch1 and Notch2, sebaceous glands are missing altogether (Pan et al. 2004). Conditional gene targeting of $R B P-J K$ also results in hair loss and epidermal cyst formation (Yamamoto et al. 2003).

Related to the natural role of Notch signaling in skin, loss of Notch 1 potentiates skin tumor development upon chemically induced carcinogenesis (Nicolas et al. 2003). Conversely, NICD overexpression in cultured cells inhibits keratinocyte proliferation, in part by upregulating the p21 target gene, which possesses a functional RBP-JK-binding site within its promoter (Rangarajan et al. 2001). Although these studies point to a role for Notch in hair differentiation and inhibition of proliferation, sustained activation of Notch signaling through NICD1 overexpression in hair shaft progenitors unexpectedly promotes matrix cell proliferation and impairs hair shaft differentiation (Lin \& Kopan 2003, Lin et al. 2000). These findings raise the possibility that the roles for Notch signaling in the epidermis and HF may be distinct.

Further insights into Notch signaling in the skin come from studies on chicken feather formation. As in mice, Notch1 is expressed in chick epidermal placode, and delta is expressed in the underlying mesenchyme. Delta overexpression in a small epidermal patch leads to an 
acceleration of feather development, whereas massive overexpression in the epidermis leads to a decrease in feather development (Crowe et al. 1998). These findings suggest a model in which Notch signaling promotes HF development in the preexisting placode but restricts neighboring cells from adopting a similar fate. The generalization of this model for other appendage development in other species requires further investigation, but the model mirrors that of Notch signaling in epidermal and neural fate specification in Drosophila.

Although loss of Notchl in the epidermis does not impair early follicle morphogenesis, it does progressively reduce the number of HFs over time (Vauclair et al. 2005). It is still unclear what the downstream genes regulated by Notch signaling in the epidermis are, and how these genes mediate their cellular function. It also remains to be determined how Notch signaling acts in the bulge SC niche, how Notch regulates hair cycle, and how the Notch signaling pathway is connected to the other signaling pathways known to influence SC maintenance and activation.

\section{CONCLUSIONS}

In summary, the function of these four signaling pathways (Wnt/ $\beta$-catenin, Shh, BMP, and Notch) is conserved during both HF morphogenesis and adult HF regeneration (Figure 8). Wnt/ $\beta$-catenin acts to specify the hair placode and bulge SC identity, and it seems to function in SC activation. It is still unclear whether the activation of the Wnt/ $\beta$-catenin pathway is caused by a decrease of a Wnt inhibitor and/or an increase of a Wnt activator. Shh acts genetically downstream of $\mathrm{Wnt} / \beta$-catenin and is necessary for the proliferation of both embryonic and adult hair germs during HF progression. It remains to be determined whether Shh is a direct $\mathrm{Wnt} / \beta$-catenin target in the adult SC or whether Shh is activated by an intermediary. HF differentiation into the IRS and hair shaft cells is controlled by both BMP and Notch. It is currently unknown whether these two pathways intersect, but BMP is necessary for the expression of nuclear $\beta$-catenin found during terminal differentiation of the hair shaft precursor cells.

\section{OTHER GENES IMPLICATED IN SKIN STEM CELL BIOLOGY}

The ends of chromosomes are called telomeres, and they consist of short, tandem DNA sequence repeats that associate with specific proteins and protect chromosome ends from degradation and recombination. Telomerase is a reverse transcriptase that synthesizes the DNA repeats to circumvent telomere shortening during DNA replication. Telomerase reverse transcriptase (TERT) is the catalytic subunit of the protein complex that makes the telomerase. Telomerase is upregulated in many human cancers, and TERT cooperates with other oncogenes to transform normal cells into tumor cells (Blackburn 2001).

TERT has been postulated to extend the proliferative potential of cells, and hence it has been speculated to play a role in SC biology. When the K5 promoter is used to drive TERT overexpression in the basal epidermal layer of transgenic mice, animals are more susceptible to skin tumorigenesis when exposed to chemical carcinogens, and they repair their wounds more rapidly (Gonzalez-Suarez et al. 2001). Conversely, mice deficient for TERC, another key component of telomerase, are resistant to skin chemical carcinogenesis (Gonzalez-Suarez et al. 2000).

In bulge SCs, increased TERT activity results in proliferation and premature entry into the anagen stage (Flores et al. 2005, Sarin et al. 2005). Flores et al. (2005) assumed that the reduced epidermal proliferation seen in $T E R C$-null mice reflected the importance of telomerase and telomere length in bulge SC behavior. In contrast, Sarin et al. (2005) discovered surprisingly that TERC affects the skin in a fashion independent of its role in telomerase function and telomere length. Both groups have posited that TERT and TERC exert their function on the quiescent SCs within the bulge. However, given the need to sustain proliferation in the matrix 
cells during the growth phase of the hair cycle, it seems more plausible that a need for enhancing conventional telomerase activity would be felt by the proliferating matrix compartment rather than the infrequently cycling cells of the bulge. Additional studies are needed to clarify these conflicting results and determine the mechanism by which telomerase overexpression allows or facilitates skin carcinogenesis and SC activation.

Bulge SCs display elevated levels of several cytoskeleton-related genes known to be regulated by small $\mathrm{G}$ proteins of the Rho family of small GTPases. Rac is a pleiotropic regulator of actin dynamics, intercellular adhesion, and cell migration, and as such, it is expressed broadly in proliferating cells. Conditional ablation of the Racl gene in the proliferating keratinocytes of skin rapidly depletes the proliferative compartments, leading to a mobilization and depletion of SCs (Benitah et al. 2005).

A priori, a similar outcome might be expected for the depletion of many different types of essential epidermal genes. However, Rac1 was of particular intrigue to Watt and her colleagues (Arnold \& Watt 2001, Braun et al. 2003, Frye et al. 2003, Waikel et al. 2001) because it is a negative regulator of c-Myc, whose elevated expression has been reported to deplete the population of bulge LRCs. It will be interesting in the future to see the extent to which, as posited by the authors, Rac1 may act at the nexus of the transition between the SC and its committed progeny (Benitah et al. 2005).

Given the general consensus that overexpression of c-Myc depletes bulge SCs and drives them to differentiate along the epidermal lineage (Arnold \& Watt 2001, Braun et al. 2003, Frye et al. 2003, Waikel et al. 2001), it came as a surprise that conditional loss of endogenous c-Myc also leads to a loss of bulge LRCs and precocious differentiation of basal epidermal cells (Zanet et al. 2005). Although the jury is still out, one possible explanation for the seemingly disparate results between gain and loss of c-Myc function is that c-Myc acts at multiple points along the bulge SC lineages, and a perturbation at one or more of these steps may indirectly impact the behavior of SCs. Consistent with this notion is that both gain- and loss-of-function studies point to a role for c-Myc in governing the sebaceous gland lineage, which is also thought to rely on bulge SCs.

\section{SUMMARY POINTS}

1. The skin epithelium is a complex tissue containing three distinct lineages that form the IFE, the HF, and the sebaceous gland.

2. The IFE constantly self-renews to provide a new protective layer at the skin surface, and HFs undergo a perpetual cycle of growth and degeneration to ensure the renewal of the hair pelage.

3. Different populations of progenitor cells contribute to lineage homeostasis, but to date, only bulge SCs have been demonstrated clonally to be multipotent with the ability to differentiate into all three differentiation lineages.

4. Bulge SCs can be activated and mobilized, at each cycle of hair follicle regeneration and after wound healing, to provide cells for tissue repair.

5. Recent progress in the isolation and molecular characterization of bulge SCs has provided new insights into the various mechanisms implicated in SC maintenance and activation.

6. Conserved signaling pathways regulating developmental decisions throughout the animal kingdom are reutilized during adult life to regulate the functions of skin 
epithelial SCs, and deregulation of these signaling pathways leads to the development of cancer in various tissues.

\section{FUTURE DIRECTIONS}

In this review, we try to highlight some of the significant advances made recently in skin stem cell biology, and we place them within the context of the historical foundations that made this current research possible. In closing, we offer a few of the unanswered questions in the field of skin stem cells that we think are likely to capture the attention of skin biologists in the years to come.

1. Do common molecular mechanisms govern the fundamental characteristics shared by adult skin SCs and other SCs, namely self-renewal and maintenance of the undifferentiated state? Comparisons of the transcriptional profiles of different types of SCs isolated directly from their respective tissues should help to identify possible candidates, as will the profiling of SCs residing in and out of their niches, and in quiescent and activated states. As candidate genes are identified, functional analyses of putative self-renewal or differentiation inhibitory SC genes in skin should reveal their importance and begin to unravel the pathways involved.

2. What is the mechanism by which quiescent bulge SCs are activated? Little is known about the signals needed to mobilize bulge SCs to reepithelialize epidermal wounds and to replenish the sebaceous gland. Even for the better understood process of SC activation during the hair cycle, a number of key issues remain unsolved. At the crux of the problem is whether follicle SC activation involves an intrinsic clock mechanism and/or whether it involves a signal from the DP. Although a change in the status of Lef1/Tcf/ $\beta$-catenin-regulated genes has been implicated in follicle SC activation, it is still not clear where a Wnt signal is involved, where it comes from, how the pathway exerts its effects, how it converges with other key signaling pathways, and how the program of gene expression is established that leads to follicle formation.

3. What is the relationship between the bulge SCs and the proliferative compartments of the epidermis, sebaceous gland, and HF? Do proliferating skin keratinocytes retain unipotent or even multipotent SC properties, or are they committed to embark on a terminal differentiation program? The point of no return in the skin SC field is an important one. Lineage-tracing experiments and the recent studies on asymmetric cell divisions in the skin provide new insights into these issues, but additional studies are now needed to illuminate the molecular relations between these different proliferative populations within the skin.

4. What is the relationship between the multipotent progenitors of embryonic skin epidermis and the multipotent SCs of the bulge? Embryonic skin effectively begins as a single layer of multipotent progenitors, but they differ from bulge SCs in their proliferative status and their lack of an apparent niche. Are bulge SCs simple quiescent counterparts of their embryonic brethren, or are there intrinsic differences between them? As methods are honed to isolate and characterize the early embryonic SCs, this relationship should become clearer. Additionally, it will be helpful to trace the development of the bulge from its early origins to its site in the postnatal follicle.

5. Are SCs at the root of cancers in the skin? Cancer is the result of a multistep process requiring the accumulation of mutations in several genes. For most cancers, the target cells of oncogenic mutations are unknown. Adult SCs may be the initial 
target cells, as they self-renew for extended periods of time, providing increased opportunity to accumulate the mutations required for cancer formation. Certain cancers contain cells with SC characteristics with high self-renewal capacities and the ability to re-form the parental tumor on transplantation. However, whether the initial oncogenic mutations arise in normal SCs or in more differentiated cells that reacquire SC-like properties remains to be determined. The demonstrations that SCs are the target cells of the initial transforming events and that cancers contain cells with SC characteristics await the development of tools allowing for the isolation and characterization of normal adult SCs. For most epithelia in which cancer arises, such isolation techniques are not available. The new methods to isolate and specifically mark skin SCs make it now possible to test experimentally the cancer SC hypothesis in the skin.

\section{ACKNOWLEDGMENTS}

We would like to thank all our colleagues in the scientific community for their many seminal contributions and insights to the field of epithelial skin biology. We apologize to those whose papers are not cited or discussed owing to space constraints. We also extend a special thank you to current members of the Fuchs lab who provided thoughtful comments about the manuscript. Elaine Fuchs is an investigator of the Howard Hughes Medical Institute, and Cédric Blanpain is a long-term fellow of the HFSPO.

\section{LITERATURE CITED}

Adolphe C, Narang M, Ellis T, Wicking C, Kaur P, Wainwright B. An in vivo comparative study of sonic, desert and Indian hedgehog reveals that hedgehog pathway activity regulates epidermal stem cell homeostasis. Development 2004;131:5009-19. [PubMed: 15371305]

Alonso L, Fuchs E. Stem cells in the skin: waste not, Wnt not. Genes Dev 2003;17:1189-200. [PubMed: 12756224]

Andl T, Ahn K, Kairo A, Chu EY, Wine-Lee L, et al. Epithelial Bmprla regulates differentiation and proliferation in postnatal hair follicles and is essential for tooth development. Development 2004;131:2257-68. [PubMed: 15102710]

Andl T, Reddy ST, Gaddapara T, Millar SE. WNT signals are required for the initiation of hair follicle development. Dev. Cell 2002;2:643-53. [PubMed: 12015971]

Argyris T. Kinetics of epidermal production during epidermal regeneration following abrasion in mice. Am. J. Pathol 1976;83:329-40. [PubMed: 1266945]

Arnold I, Watt FM. c-Myc activation in transgenic mouse epidermis results in mobilization of stem cells and differentiation of their progeny. Curr. Biol 2001;11:558-68. [PubMed: 11369200]

Artavanis-Tsakonas S, Rand MD, Lake RJ. Notch signaling: cell fate control and signal integration in development. Science 1999;284:770-76. [PubMed: 10221902]

Barrandon Y, Green H. Three clonal types of keratinocyte with different capacities for multiplication. Proc. Natl. Acad. Sci. USA 1987;84:2302-6. [PubMed: 2436229]

Beaudoin GM, Sisk JM, Coulombe PA, Thompson CC. Hairless triggers reactivation of hair growth by promoting Wnt signaling. Proc. Natl. Acad. Sci. USA 2005;102:14653-58. [PubMed: 16195376]

Benitah SA, Frye M, Glogauer M, Watt FM. Stem cell depletion through epidermal deletion of Rac1. Science 2005;309:933-35. [PubMed: 16081735]

Bickenbach JR. Identification and behavior of label-retaining cells in oral mucosa and skin. J. Dent. Res 1981;60(Spec No C):1611-20. [PubMed: 6943171]

Blackburn EH. Switching and signaling at the telomere. Cell 2001;106:661-73. [PubMed: 11572773]

Blanpain C, Lowry WE, Geoghegan A, Polak L, Fuchs E. Self-renewal, multipotency, and the existence of two cell populations within an epithelial stem cell niche. Cell 2004;118:635-48. [PubMed: 15339667]

Botchkarev VA, Botchkareva NV, Nakamura M, Huber O, Funa K, et al. Noggin is required for induction of the hair follicle growth phase in postnatal skin. FASEB J 2001;15:2205-14. [PubMed: 11641247] 
Botchkarev VA, Botchkareva NV, Roth W, Nakamura M, Chen LH, et al. Noggin is a mesenchymally derived stimulator of hair-follicle induction. Nat. Cell Biol 1999;1:158-64. [PubMed: 10559902]

Braun KM, Niemann C, Jensen UB, Sundberg JP, Silva-Vargas V, Watt FM. Manipulation of stem cell proliferation and lineage commitment: visualisation of label-retaining cells in wholemounts of mouse epidermis. Development 2003;130:5241-55. [PubMed: 12954714]

Candi E, Schmidt R, Melino G. The cornified envelope: a model of cell death in the skin. Nat. Rev. Mol. Cell Biol 2005;6:328-40. [PubMed: 15803139]

Casali A, Struhl G. Reading the Hedgehog morphogen gradient by measuring the ratio of bound to unbound Patched protein. Nature 2004;431:76-80. [PubMed: 15300262]

Chan EF, Gat U, McNiff JM, Fuchs E. A common human skin tumor is caused by activating mutations in $\beta$-catenin. Nat. Genet 1999;21:410-13. [PubMed: 10192393]

Chiang C, Swan RZ, Grachtchouk M, Bolinger M, Litingtung Y, et al. Essential role for Sonic hedgehog during hair follicle morphogenesis. Dev. Biol 1999;205:1-9. [PubMed: 9882493]

Claudinot S, Nicolas M, Oshima H, Rochat A, Barrandon Y. Long-term renewal of hair follicles from clonogenic multipotent stem cells. Proc. Natl. Acad. Sci. USA 2005;102:14677-82. [PubMed: 16203973]

Cotsarelis G, Sun TT, Lavker RM. Label-retaining cells reside in the bulge area of pilosebaceous unit: implications for follicular stem cells, hair cycle, and skin carcinogenesis. Cell 1990;61:1329-37. [PubMed: 2364430]

Cowan CR, Hyman AA. Asymmetric cell division in C. elegans: cortical polarity and spindle positioning. Annu. Rev. Cell Dev. Biol 2004;20:427-53. [PubMed: 15473847]

Crowe R, Henrique D, Ish-Horowicz D, Niswander L. A new role for Notch and Delta in cell fate decisions: patterning the feather array. Development 1998;125:767-75. [PubMed: 9435296]

Dahmane N, Lee J, Robins P, Heller P, Ruiz Altaba A. Activation of the transcription factor Gli1 and the Sonic hedgehog signaling pathway in skin tumours. Nature 1997;389:876-81. [PubMed: 9349822]

Dai X, Segre JA. Transcriptional control of epidermal specification and differentiation. Curr. Opin. Genet. Dev 2004;14:485-91. [PubMed: 15380238]

DasGupta R, Fuchs E. Multiple roles for activated LEF/TCF transcription complexes during hair follicle development and differentiation. Development 1999;126:4557-68. [PubMed: 10498690]

Flores I, Cayuela ML, Blasco MA. Effects of telomerase and telomere length on epidermal stem cell behavior. Science 2005;309:1253-56. [PubMed: 16037417]

Frye M, Gardner C, Li ER, Arnold I, Watt FM. Evidence that Myc activation depletes the epidermal stem cell compartment by modulating adhesive interactions with the local microenvironment. Development 2003;130:2793-808. [PubMed: 12736221]

Fuchs E. Keratins and the skin. Annu. Rev. Cell Dev. Biol 1995;11:123-53. [PubMed: 8689554]

Gailani MR, Stahle-Backdahl M, Leffell DJ, Glynn M, Zaphiropoulos PG, et al. The role of the human homologue of Drosophila patched in sporadic basal cell carcinomas. Nat. Genet 1996;14:78-81. [PubMed: 8782823]

Gallico GG, O'Connor NE, Compton CC, Kehinde O, Green H. Permanent coverage of large burn wounds with autologous cultured human epithelium. N. Engl. J. Med 1984;311:448-51. [PubMed: 6379456]

Gat U, DasGupta R, Degenstein L, Fuchs E. De novo hair follicle morphogenesis and hair tumors in mice expressing a truncated $\beta$-catenin in skin. Cell 1998;95:605-14. [PubMed: 9845363]

Ghazizadeh S, Taichman LB. Multiple classes of stem cells in cutaneous epithelium: a lineage analysis of adult mouse skin. EMBO J 2001;20:1215-22. [PubMed: 11250888]

Gonzalez-Suarez E, Samper E, Flores JM, Blasco MA. Telomerase-deficient mice with short telomeres are resistant to skin tumorigenesis. Nat. Genet 2000;26:114-17. [PubMed: 10973262]

Gonzalez-Suarez E, Samper E, Ramirez A, Flores JM, Martin-Caballero J, et al. Increased epidermal tumors and increased skin wound healing in transgenic mice overexpressing the catalytic subunit of telomerase, mTERT, in basal keratinocytes. EMBO J 2001;20:2619-30. [PubMed: 11387197]

Grachtchouk M, Mo R, Yu S, Zhang X, Sasaki H, et al. Basal cell carcinomas in mice overexpressing Gli2 in skin. Nat. Genet 2000;24:216-17. [PubMed: 10700170]

Grachtchouk V, Grachtchouk M, Lowe L, Johnson T, Wei L, et al. The magnitude of hedgehog signaling activity defines skin tumor phenotype. EMBO J 2003;22:2741-51. [PubMed: 12773389] 
Green KJ, Bohringer M, Gocken T, Jones JC. Intermediate filament associated proteins. Adv. Protein Chem 2005;70:143-202. [PubMed: 15837516]

Guo L, Yu QC, Fuchs E. Targeting expression of keratinocyte growth factor to keratinocytes elicits striking changes in epithelial differentiation in transgenic mice. EMBO J 1993;12:973-86. [PubMed: 7681397]

Hahn H, Wicking C, Zaphiropoulous PG, Gailani MR, Shanley S, et al. Mutations of the human homolog of Drosophila patched in the nevoid basal cell carcinoma syndrome. Cell 1996;85:841-51. [PubMed: 8681379]

Hardy MH. The secret life of the hair follicle. Trends Genet 1992;8:55-61. [PubMed: 1566372]

Huelsken J, Vogel R, Erdmann B, Cotsarelis G, Birchmeier W. $\beta$-Catenin controls hair follicle morphogenesis and stem cell differentiation in the skin. Cell 2001;105:533-45. [PubMed: 11371349]

Hutchin ME, Kariapper MS, Grachtchouk M, Wang A, Wei L, et al. Sustained Hedgehog signaling is required for basal cell carcinoma proliferation and survival: conditional skin tumorigenesis recapitulates the hair growth cycle. Genes Dev 2005;19:214-23. [PubMed: 15625189]

Ito M, Kizawa K. Expression of calcium-binding S100 proteins A4 and A6 in regions of the epithelial sac associated with the onset of hair follicle regeneration. J. Invest. Dermatol 2001;116:956-63. [PubMed: 11407987]

Ito M, Liu Y, Yang Z, Nguyen J, Liang F, et al. Stem cells in the hair follicle bulge contribute to wound repair but not to homeostasis of the epidermis. Nat. Med 2005;11:1351-54. [PubMed: 16288281]

Ivanova NB, Dimos JT, Schaniel C, Hackney JA, Moore KA, Lemischka IR. A stem cell molecular signature. Science 2002;298:601-4. [PubMed: 12228721]

Jahoda CA, Horne KA, Oliver RF. Induction of hair growth by implantation of cultured dermal papilla cells. Nature 1984;311:560-62. [PubMed: 6482967]

Jamora C, DasGupta R, Kocieniewski P, Fuchs E. Links between signal transduction, transcription and adhesion in epithelial bud development. Nature 2003;422:317-22. [PubMed: 12646922]

Johnson RL, Rothman AL, Xie J, Goodrich LV, Bare JW, et al. Human homolog of patched, a candidate gene for the basal cell nevus syndrome. Science 1996;272:1668-71. [PubMed: 8658145]

Jones PH, Harper S, Watt FM. Stem cell patterning and fate in human epidermis. Cell 1995;80:83-93. [PubMed: 7813021]

Jones PH, Watt FM. Separation of human epidermal stem cells from transit amplifying cells on the basis of differences in integrin function and expression. Cell 1993;73:713-24. [PubMed: 8500165]

Kaufman CK, Zhou P, Pasolli HA, Rendl M, Bolotin D, et al. GATA-3: an unexpected regulator of cell lineage determination in skin. Genes Dev 2003;17:2108-22. [PubMed: 12923059]

Kligman AM. The human hair cycle. J. Invest. Dermatol 1959;33:307-16. [PubMed: 14409844]

Kobayashi K, Rochat A, Barrandon Y. Segregation of keratinocyte colony-forming cells in the bulge of the rat vibrissa. Proc. Natl. Acad. Sci. USA 1993;90:7391-95. [PubMed: 8346261]

Kobielak K, Pasolli HA, Alonso L, Polak L, Fuchs E. Defining BMP functions in the hair follicle by conditional ablation of BMP receptor IA. J. Cell Biol 2003;163:609-23. [PubMed: 14610062]

Kolodka TM, Garlick JA, Taichman LB. Evidence for keratinocyte stem cells in vitro: long term engraftment and persistence of transgene expression from retrovirus-transduced keratinocytes. Proc. Natl. Acad. Sci. USA 1998;95:4356-61. [PubMed: 9539741]

Kopan R, Weintraub H. Mouse notch: expression in hair follicles correlates with cell fate determination. J. Cell Biol 1993;121:631-41. [PubMed: 8486742]

Kratochwil K, Dull M, Farinas I, Galceran J, Grosschedl R. Lef1 expression is activated by BMP-4 and regulates inductive tissue interactions in tooth and hair development. Genes Dev 1996;10:1382-94. [PubMed: 8647435]

Kulessa H, Turk G, Hogan BL. Inhibition of Bmp signaling affects growth and differentiation in the anagen hair follicle. EMBO J 2000;19:6664-74. [PubMed: 11118201]

Lavker RM, Sun TT. Heterogeneity in epidermal basal keratinocytes: morphological and functional correlations. Science 1982;215:1239-41. [PubMed: 7058342]

Lechler T, Fuchs E. Asymmetric cell divisions promote stratification and differentiation of mammalian skin. Nature 2005;437:275-80. [PubMed: 16094321] 
Legg J, Jensen UB, Broad S, Leigh I, Watt FM. Role of melanoma chondroitin sulphate proteoglycan in patterning stem cells in human interfollicular epidermis. Development 2003;130:6049-63. [PubMed: 14573520]

Levy V, Lindon C, Harfe BD, Morgan BA. Distinct stem cell populations regenerate the follicle and interfollicular epidermis. Dev. Cell 2005;9:855-61. [PubMed: 16326396]

Li A, Simmons PJ, Kaur P. Identification and isolation of candidate human keratinocyte stem cells based on cell surface phenotype. Proc. Natl. Acad. Sci. USA 1998;95:3902-7. [PubMed: 9520465]

Lin MH, Kopan R. Long-range, nonautonomous effects of activated Notch1 on tissue homeostasis in the nail. Dev. Biol 2003;263:343-59. [PubMed: 14597207]

Lin MH, Leimeister C, Gessler M, Kopan R. Activation of the Notch pathway in the hair cortex leads to aberrant differentiation of the adjacent hair-shaft layers. Development 2000;127:2421-32. [PubMed: 10804183]

Lo Celso C, Prowse DM, Watt FM. Transient activation of $\beta$-catenin signaling in adult mouse epidermis is sufficient to induce new hair follicles but continuous activation is required to maintain hair follicle tumours. Development 2004;131:1787-99. [PubMed: 15084463]

Logan CY, Nusse R. The Wnt signaling pathway in development and disease. Annu. Rev. Cell Dev. Biol 2004;20:781-810. [PubMed: 15473860]

Lowry WE, Blanpain C, Nowak JA, Guasch G, Lewis L, Fuchs E. Defining the impact of $\beta$-catenin/Tcf transactivation on epithelial stem cells. Genes Dev 2005;19:1596-611. [PubMed: 15961525]

Lyle S, Christofidou-Solomidou M, Liu Y, Elder DE, Albelda S, Cotsarelis G. The C8/144B monoclonal antibody recognizes cytokeratin 15 and defines the location of human hair follicle stem cells. J. Cell Sci 1998;111(Pt 21):3179-88. [PubMed: 9763512]

Lyons KM, Pelton RW, Hogan BL. Patterns of expression of murine Vgr-1 and BMP-2a RNA suggest that transforming growth factor- $\beta$-like genes coordinately regulate aspects of embryonic development. Genes Dev 1989;3:1657-68. [PubMed: 2481605]

Lyons KM, Pelton RW, Hogan BL. Organogenesis and pattern formation in the mouse: RNA distribution patterns suggest a role for bone morphogenetic protein-2A (BMP-2A). Development 1990;109:83344. [PubMed: 2226202]

Mackenzie IC. Relationship between mitosis and the ordered structure of the stratum corneum in mouse epidermis. Nature 1970;226:653-55. [PubMed: 5444930]

Mackenzie IC. Retroviral transduction of murine epidermal stem cells demonstrates clonal units of epidermal structure. J. Invest. Dermatol 1997;109:377-83. [PubMed: 9284108]

Merrill BJ, Gat U, DasGupta R, Fuchs E. Tcf3 and Lef1 regulate lineage differentiation of multipotent stem cells in skin. Genes Dev 2001;15:1688-705. [PubMed: 11445543]

Merrill BJ, Pasolli HA, Polak L, Rendl M, Garcia-Garcia MJ, et al. Tcf3: a transcriptional regulator of axis induction in the early embryo. Development 2004;131:263-74. [PubMed: 14668413]

Michel M, Torok N, Godbout MJ, Lussier M, Gaudreau P, et al. Keratin 19 as a biochemical marker of skin stem cells in vivo and in vitro: keratin 19 expressing cells are differentially localized in function of anatomic sites, and their number varies with donor age and culture stage. J. Cell Sci 1996;109(Pt 5):1017-28. [PubMed: 8743949]

Mill P, Mo R, Fu H, Grachtchouk M, Kim PC, et al. Sonic hedgehog-dependent activation of Gli2 is essential for embryonic hair follicle development. Genes Dev 2003;17:282-94. [PubMed: 12533516]

Millar SE. Molecular mechanisms regulating hair follicle development. J. Invest. Dermatol 2002;118:216-25. [PubMed: 11841536]

Mills AA, Zheng B, Wang XJ, Vogel H, Roop DR, Bradley A. p63 is a p53 homologue required for limb and epidermal morphogenesis. Nature 1999;398:708-13. [PubMed: 10227293]

Ming Kwan K, Li AG, Wang XJ, Wurst W, Behringer RR. Essential roles of BMPR-IA signaling in differentiation and growth of hair follicles and in skin tumorigenesis. Genesis 2004;39:10-25. [PubMed: 15124223]

Montagna W, Chase HB. Histology and cytochemistry of human skin. X. X-irradiation of the scalp. Am. J. Anat 1956;99:415-45. [PubMed: 13402726]

Montagna W, Chase HB, Brown PJ. The skin of hairless mice. II. Ageing changes and the action of 20methylcholanthrene. J. Invest. Dermatol 1954;23:259-69. [PubMed: 13201816] 
Morris RJ, Liu Y, Marles L, Yang Z, Trempus C, et al. Capturing and profiling adult hair follicle stem cells. Nat. Biotechnol 2004;22:411-17. [PubMed: 15024388]

Muller-Rover S, Handjiski B, van der Veen C, Eichmuller S, Foitzik K, et al. A comprehensive guide for the accurate classification of murine hair follicles in distinct hair cycle stages. J. Invest. Dermatol 2001;117:3-15. [PubMed: 11442744]

Nicolas M, Wolfer A, Raj K, Kummer JA, Mill P, et al. Notch1 functions as a tumor suppressor in mouse skin. Nat. Genet 2003;33:416-21. [PubMed: 12590261]

Niemann C, Unden AB, Lyle S, Zouboulis CC, Toftgard R, Watt FM. Indian hedgehog and $\beta$-catenin signaling: role in the sebaceous lineage of normal and neoplastic mammalian epidermis. Proc. Natl. Acad. Sci. USA 2003;100(Suppl 1):11873-80. [PubMed: 12917489]

Nikaido M, Tada M, Takeda H, Kuroiwa A, Ueno N. In vivo analysis using variants of zebrafish BMPRIA: range of action and involvement of BMP in ectoderm patterning. Development 1999;126:18190. [PubMed: 9834197]

O'Connor NE, Mulliken JB, Banks-Schlegel S, Kehinde O, Green H. Grafting of burns with cultured epithelium prepared from autologous epidermal cells. Lancet 1981;1:75-78. [PubMed: 6109123]

O'Guin WM, Sun TT, Manabe M. Interaction of trichohyalin with intermediate filaments: three immunologically defined stages of trichohyalin maturation. J. Invest. Dermatol 1992;98:24-32. [PubMed: 1728637]

Ohyama M, Terunuma A, Tock CL, Radonovich MF, Pise-Masison CA, et al. Characterization and isolation of stem cell-enriched human hair follicle bulge cells. J. Clin. Invest 2006;116:249-60. [PubMed: 16395407]

Okuyama R, Nguyen BC, Talora C, Ogawa E, Tommasi di Vignano A, et al. High commitment of embryonic keratinocytes to terminal differentiation through a Notch1-caspase 3 regulatory mechanism. Dev. Cell 2004;6:551-62. [PubMed: 15068794]

Oliver RF. Histological studies of whisker regeneration in the hooded rat. J. Embryol. Exp. Morphol 1966;16:231-44. [PubMed: 5971987]

Oliver RF. The experimental induction of whisker growth in the hooded rat by implantation of dermal papillae. J. Embryol. Exp. Morphol 1967;18:43-51. [PubMed: 6048979]

Omary MB, Coulombe PA, McLean WH. Intermediate filament proteins and their associated diseases. N. Engl. J. Med 2004;351:2087-900. [PubMed: 15537907]

Oro AE, Higgins K. Hair cycle regulation of Hedgehog signal reception. Dev. Biol 2003;255:238-48. [PubMed: 12648487]

Oro AE, Higgins KM, Hu Z, Bonifas JM, Epstein EHJ, Scott MP. Basal cell carcinomas in mice overexpressing sonic hedgehog. Science 1997;276:817-21. [PubMed: 9115210]

Oshima H, Rochat A, Kedzia C, Kobayashi K, Barrandon Y. Morphogenesis and renewal of hair follicles from adult multipotent stem cells. Cell 2001;104:233-45. [PubMed: 11207364]

Paladini RD, Saleh J, Qian C, Xu GX, Rubin LL. Modulation of hair growth with small molecule agonists of the hedgehog signaling pathway. J. Invest. Dermatol 2005;125:638-46. [PubMed: 16185261]

Pan Y, Lin MH, Tian X, Cheng HT, Gridley T, et al. $\gamma$-Secretase functions through Notch signaling to maintain skin appendages but is not required for their patterning or initial morphogenesis. Dev. Cell 2004;7:731-43. [PubMed: 15525534]

Paus R, Muller-Rover S, Van Der Veen C, Maurer M, Eichmuller S, et al. A comprehensive guide for the recognition and classification of distinct stages of hair follicle morphogenesis. J. Invest. Dermatol 1999;113:523-32. [PubMed: 10504436]

Pellegrini G, Ranno R, Stracuzzi G, Bondanza S, Guerra L, et al. The control of epidermal stem cells (holoclones) in the treatment of massive full-thickness burns with autologous keratinocytes cultured on fibrin. Transplantation 1999;68:868-79. [PubMed: 10515389]

Perez-Moreno M, Jamora C, Fuchs E. Sticky business: orchestrating cellular signals at adherens junctions. Cell 2003;112:535-48. [PubMed: 12600316]

Petiot A, Conti FJ, Grose R, Revest JM, Hodivala-Dilke KM, Dickson C. A crucial role for Fgfr2-IIIb signaling in epidermal development and hair follicle patterning. Development 2003;130:5493-501. [PubMed: 14530295]

Potten CS. The epidermal proliferative unit: the possible role of the central basal cell. Cell Tissue Kinet 1974;7:77-88. [PubMed: 4129708] 
Potten CS. Cell replacement in epidermis (keratopoiesis) via discrete units of proliferation. Int. Rev. Cytol 1981;69:271-318. [PubMed: 6163744]

Potten CS, Wichmann HE, Loeffler M, Dobek K, Major D. Evidence for discrete cell kinetic subpopulations in mouse epidermis based on mathematical analysis. Cell Tissue Kinet 1982;15:305-29. [PubMed: 7083300]

Ramalho-Santos M, Yoon S, Matsuzaki Y, Mulligan RC, Melton DA. "Stemness": transcriptional profiling of embryonic and adult stem cells. Science 2002;298:597-600. [PubMed: 12228720]

Rangarajan A, Talora C, Okuyama R, Nicolas M, Mammucari C, et al. Notch signaling is a direct determinant of keratinocyte growth arrest and entry into differentiation. EMBO J 2001;20:342736. [PubMed: 11432830]

Rendl M, Lewis L, Fuchs E. Molecular dissection of mesenchymal-epithelial interactions in the hair follicle. PLoS Biol 2005;3:e:331. [PubMed: 16162033]

Reya T, Clevers H. Wnt signaling in stem cells and cancer. Nature 2005;434:843-50. [PubMed: 15829953]

Reya T, Morrison SJ, Clarke MF, Weissman IL. Stem cells, cancer, and cancer stem cells. Nature 2001;414:105-11. [PubMed: 11689955]

Rheinwald JG, Green H. Serial cultivation of strains of human epidermal keratinocytes: the formation of keratinizing colonies from single cells. Cell 1975;6:331-43. [PubMed: 1052771]

Ro S, Rannala B. A stop-EGFP transgenic mouse to detect clonal cell lineages generated by mutation. EMBO Rep 2004;5:914-20. [PubMed: 15297872]

Rochat A, Kobayashi K, Barrandon Y. Location of stem cells of human hair follicles by clonal analysis. Cell 1994;76:1063-73. [PubMed: 8137423]

Ronfard V, Rives JM, Neveux Y, Carsin H, Barrandon Y. Long-term regeneration of human epidermis on third degree burns transplanted with autologous cultured epithelium grown on a fibrin matrix. Transplantation 2000;70:1588-98. [PubMed: 11152220]

Rubin AI, Chen EH, Ratner D. Basal-cell carcinoma. N. Engl. J. Med 2005;353:2262-69. [PubMed: 16306523]

Sarin KY, Cheung P, Gilison D, Lee E, Tennen RI, et al. Conditional telomerase induction causes proliferation of hair follicle stem cells. Nature 2005;436:1048-52. [PubMed: 16107853]

Sato N, Leopold PL, Crystal RG. Induction of the hair growth phase in postnatal mice by localized transient expression of Sonic hedgehog. J. Clin. Invest 1999;104:855-64. [PubMed: 10510326]

Schmidt-Ullrich R, Paus R. Molecular principles of hair follicle induction and morpho-genesis. Bioessays 2005;27:247-61. [PubMed: 15714560]

Shi Y, Massague J. Mechanisms of TGF- $\beta$ signaling from cell membrane to the nucleus. Cell 2003;113:685-700. [PubMed: 12809600]

Silva-Vargas V, Lo Celso C, Giangreco A, Ofstad T, Prowse DM, et al. Beta-catenin and Hedgehog signal strength can specify number and location of hair follicles in adult epidermis without recruitment of bulge stem cells. Dev. Cell 2005;9:121-31. [PubMed: 15992546]

Smart IH. Variation in the plane of cell cleavage during the process of stratification in the mouse epidermis. Br. J. Dermatol 1970;82:276-82. [PubMed: 5441760]

St-Jacques B, Dassule HR, Karavanova I, Botchkarev VA, Li J, et al. Sonic hedgehog signaling is essential for hair development. Curr. Biol 1998;8:1058-68. [PubMed: 9768360]

Stohr P. Entwicklungsgeschichte des menschlichen Wollha. ares. Anat. Hefte 1903;23:1-66.

Taipale J, Beachy PA. The Hedgehog and Wnt signaling pathways in cancer. Nature 2001;411:349-54. [PubMed: 11357142]

Tani H, Morris RJ, Kaur P. Enrichment for murine keratinocyte stem cells based on cell surface phenotype. Proc. Natl. Acad. Sci. USA 2000;97:10960-65. [PubMed: 11005869]

Taylor G, Lehrer MS, Jensen PJ, Sun TT, Lavker RM. Involvement of follicular stem cells in forming not only the follicle but also the epidermis. Cell 2000;102:451-61. [PubMed: 10966107]

Trempus CS, Morris RJ, Bortner CD, Cotsarelis G, Faircloth RS, et al. Enrichment for living murine keratinocytes from the hair follicle bulge with the cell surface marker CD34. J. Invest. Dermatol 2003;120:501-11. [PubMed: 12648211] 
Tumbar T, Guasch G, Greco V, Blanpain C, Lowry WE, et al. Defining the epithelial stem cell niche in skin. Science 2004;303:359-63. [PubMed: 14671312]

Unden AB, Holmberg E, Lundh-Rozell B, Stahle-Backdahl M, Zaphiropoulos PG, et al. Mutations in the human homologue of Drosophila patched $(P T C H)$ in basal cell carcinomas and the Gorlin syndrome: different in vivo mechanisms of $P T C H$ inactivation. Cancer Res 1996;56:4562-65. [PubMed: 8840960]

Vaezi A, Bauer C, Vasioukhin V, Fuchs E. Actin cable dynamics and Rho/Rock orchestrate a polarized cytoskeletal architecture in the early steps of assembling a stratified epithelium. Dev. Cell 2002;3:367-81. [PubMed: 12361600]

van Genderen C, Okamura RM, Farinas I, Quo RG, Parslow TG, et al. Development of several organs that require inductive epithelial-mesenchymal interactions is impaired in LEF-1-deficient mice. Genes Dev 1994;8:2691-703. [PubMed: 7958926]

Van Mater D, Kolligs FT, Dlugosz AA, Fearon ER. Transient activation of $\beta$-catenin signaling in cutaneous keratinocytes is sufficient to trigger the active growth phase of the hair cycle in mice. Genes Dev 2003;17:1219-24. [PubMed: 12756226]

Vauclair S, Nicolas M, Barrandon Y, Radtke F. Notch1 is essential for postnatal hair follicle development and homeostasis. Dev. Biol 2005;284:184-93. [PubMed: 15978571]

Vidal VP, Chaboissier MC, Lutzkendorf S, Cotsarelis G, Mill P, et al. Sox9 is essential for outer root sheath differentiation and the formation of the hair stem cell compartment. Curr. Biol 2005;15:1340-51. [PubMed: 16085486]

Waikel RL, Kawachi Y, Waikel PA, Wang XJ, Roop DR. Deregulated expression of c-Myc depletes epidermal stem cells. Nat. Genet 2001;28:165-68. [PubMed: 11381265]

Wang LC, Liu ZY, Gambardella L, Delacour A, Shapiro R, et al. Regular articles: conditional disruption of hedgehog signaling pathway defines its critical role in hair development and regeneration. J. Invest. Dermatol 2000;114:901-8. [PubMed: 10771469]

Watt FM, Green H. Stratification and terminal differentiation of cultured epidermal cells. Nature 1982;295:434-36. [PubMed: 6895777]

Weissman IL, Anderson DJ, Gage F. Stem and progenitor cells: origins, phenotypes, lineage commitments, and transdifferentiations. Annu. Rev. Cell Dev. Biol 2001;17:387-403. [PubMed: 11687494]

Wilson N, Hynd PI, Powell BC. The role of BMP-2 and BMP-4 in follicle initiation and the murine hair cycle. Exp. Dermatol 1999;8:367-68. [PubMed: 10439283]

Wodarz A. Molecular control of cell polarity and asymmetric cell division in Drosophila neuroblasts. Curr. Opin. Cell Biol 2005;17:475-81. [PubMed: 16099639]

Xia J, Urabe K, Moroi Y, Koga T, Duan H, et al. $\beta$-Catenin mutation and its nuclear localization are confirmed to be frequent causes of Wnt signaling pathway activation in pilomatricomas. J. Dermatol. Sci 2006;41:67-75. [PubMed: 16378715]

Xie J, Murone M, Luoh SM, Ryan A, Gu Q, et al. Activating Smoothened mutations in sporadic basalcell carcinoma. Nature 1998;391:90-92. [PubMed: 9422511]

Yamamoto N, Tanigaki K, Han H, Hiai H, Honjo T. Notch/RBP-J signaling regulates epidermis/hair fate determination of hair follicular stem cells. Curr. Biol 2003;13:333-38. [PubMed: 12593800]

Yang A, Schweitzer R, Sun D, Kaghad M, Walker N, et al. p63 is essential for regenerative proliferation in limb, craniofacial and epithelial development. Nature 1999;398:714-18. [PubMed: 10227294]

Yuhki M, Yamada M, Kawano M, Iwasato T, Itohara S, et al. BMPR1A signaling is necessary for hair follicle cycling and hair shaft differentiation in mice. Development 2004;131:1825-33. [PubMed: 15084466]

Zanet J, Pibre S, Jacquet C, Ramirez A, de Alboran IM, Gandarillas A. Endogenous Myc controls mammalian epidermal cell size, hyperproliferation, endoreplication and stem cell amplification. J. Cell Sci 2005;118:1693-704. [PubMed: 15797928]

Zhou P, Byrne C, Jacobs J, Fuchs E. Lymphoid enhancer factor 1 directs hair follicle patterning and epithelial cell fate. Genes Dev 1995;9:700-13. [PubMed: 7537238] 


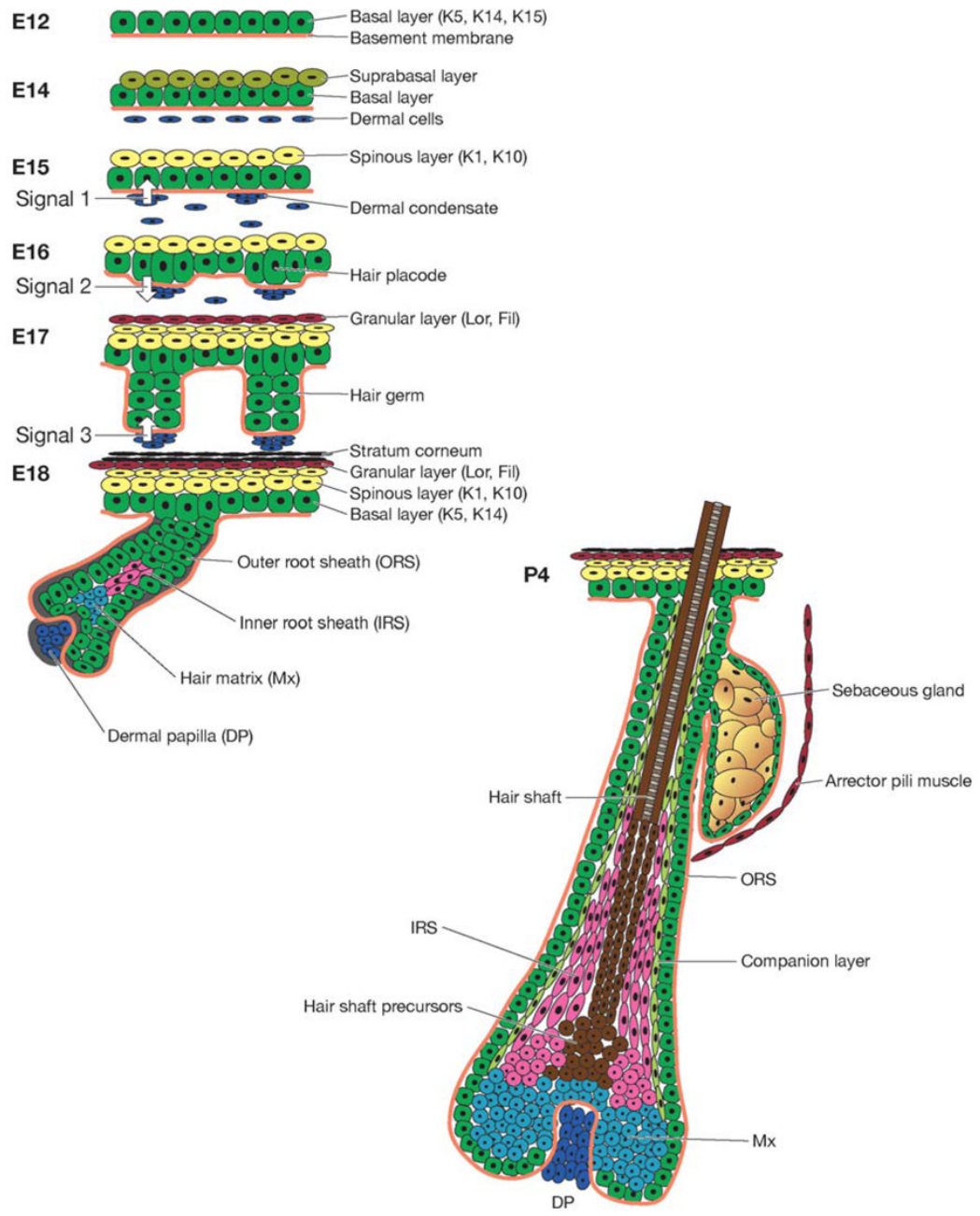

Figure 1.

Epidermal development and hair follicle morphogenesis. The surface of the early embryo is covered by a single layer of ectodermal cells that adheres to an underlying basement membrane of extracellular matrix. As development proceeds, the epidermis progressively stratifies and acquires layers of terminally differentiating cells that are required to establish a functional barrier. During embryonic development, some of the undifferentiated basal cells are instructed by the underlying dermis (signal 1) to adopt a hair follicular fate. Subsequently, the epidermis sends a message to the dermis (signal 2) to make the dermal papilla (DP). Finally, the DP sends a message to the developing follicle (signal 3), allowing its growth and differentiation to form the discrete lineages of the hair follicle and its hair. Encased by a basement membrane, the basal layer of the follicle is referred to as the outer root sheath (ORS). At the base of the mature follicle is the highly proliferative compartment called the matrix (Mx). Matrix cells differentiate to form the concentric rings of differentiating cells that give rise to the hair shaft, its channel (the inner root sheath, IRS), and the companion layer. Hair follicles also contain sebaceous glands to ensure the water impermeability of the hair and lubricate the hair channel and skin surface. 


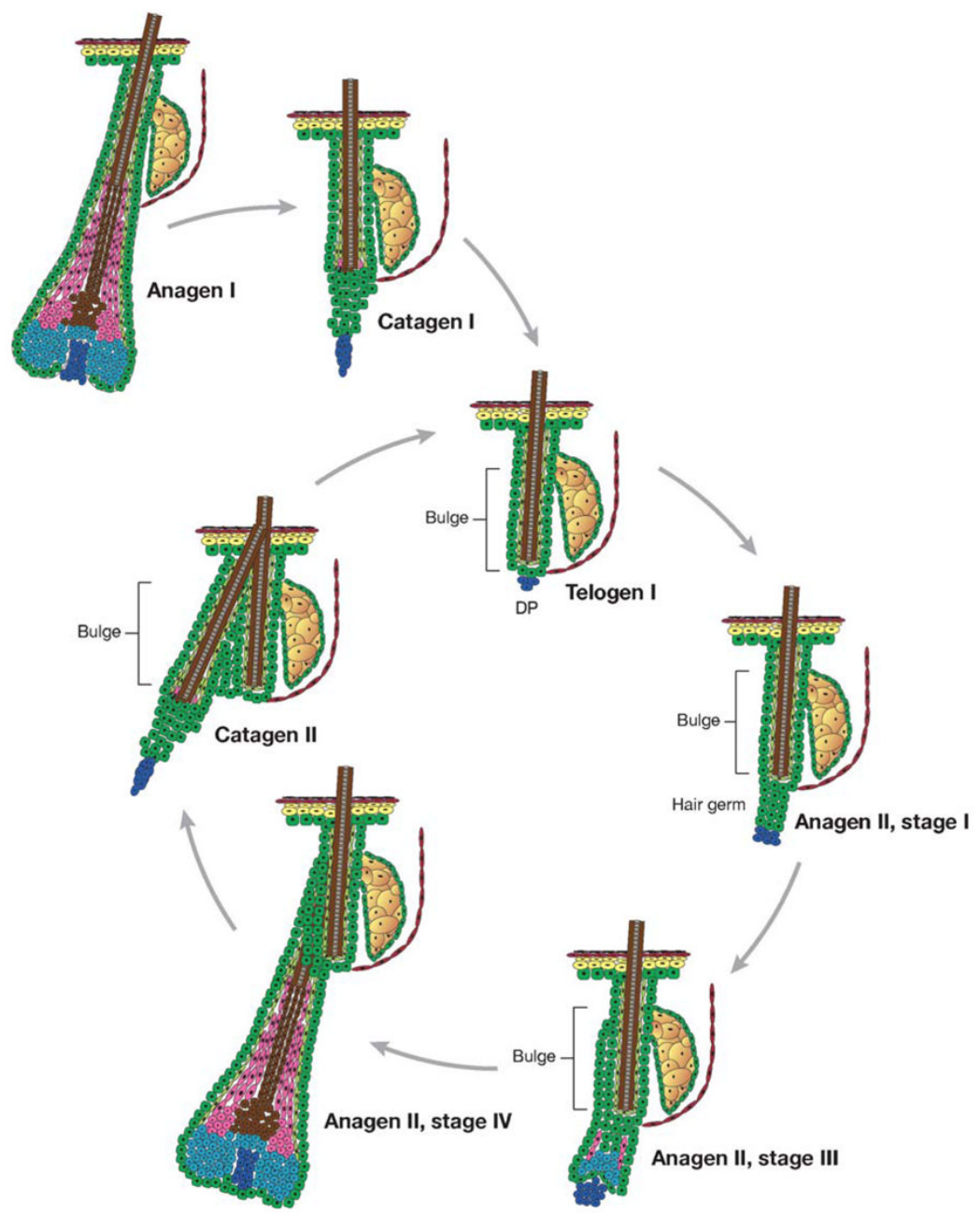

Figure 2.

The hair follicle cycle. When matrix cells exhaust their proliferative capacity or the stimulus required for it, hair growth stops. At this time, the follicle enters a destructive phase (catagen), leading to the degeneration of the lower two-thirds of the follicle. The upper third of the follicle remains intact as a pocket of cells surrounding the old hair shaft (club hair). The base of this pocket is known as the bulge, which is the natural reservoir of hair follicle stem cells (SCs) necessary to form a new hair follicle. After catagen, the bulge cells enter a quiescent stage (telogen), in which the DP is now in close contact with bulge SCs. In the mouse, the first telogen lasts approximately one day, after which all the hair follicles synchronously enter a new cycle of regeneration and hair growth (anagen stage). The bulge as a structure develops when the new hair must emerge from the original orifice, which is often shared by the old club hair. Subsequent hair cycles involve increasingly longer telogen phases, resulting in considerably less synchronous hair cycles. 
a

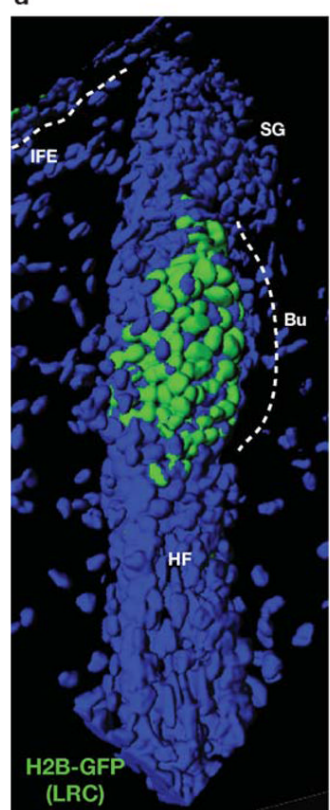

b
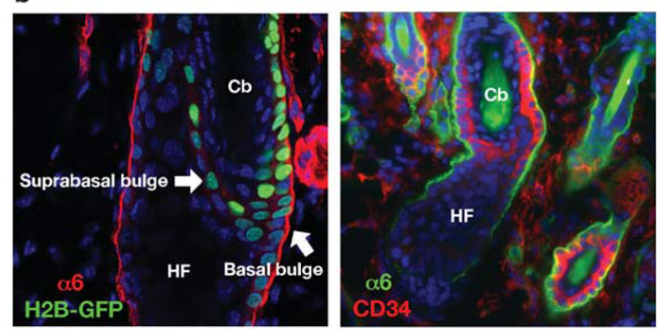

Flow cytometry of anagen epidermis

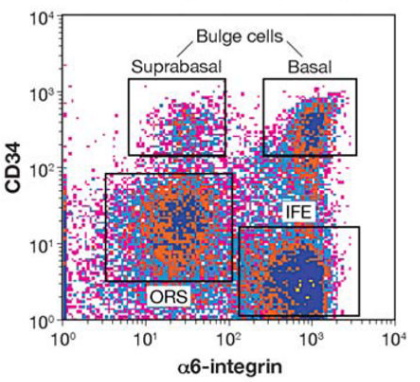

Figure 3.

The bulge stem cells (SCs). Bulge (Bu) SCs are more quiescent than are other keratinocytes with proliferative potential in the skin. Tumbar et al. (2004) developed a strategy for conducting fluorescent pulse-chase experiments in mice engineered to express a tetracycline-regulatable H2B-GFP transgene. After labeling all the skin epithelial cells with H2B-GFP, a four-week chase resulted in significant H2B-GFP-label retention only in the bulge $(a)$. Label-retaining cells (LRCs) could be found along the basal layer of cells that express $\alpha 6 \beta 4$-integrins, as well as in a suprabasal location within the bulge $(b)$. Bulge SCs express a high level of the cell surface protein CD34, which has been used with $\alpha 6$-integrin to isolate basal and suprabasal bulge cells, using flow cytometry (Blanpain et al. 2004, Trempus et al. 2003). [The approximate fluorescence of the outer root sheath (ORS) and interfollicular epidermis (IFE) cells is also indicated on the FACS profile.] Tissues were counterstained with Dapi (blue) to mark the nuclei. Abbreviations used: $\mathrm{Cb}$, club hair; $\mathrm{HF}$, hair follicle; $\mathrm{SG}$, sebaceous gland. 


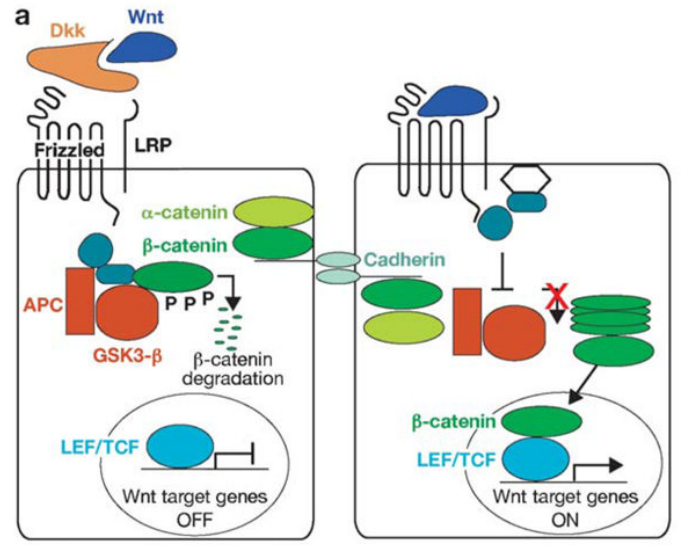

c
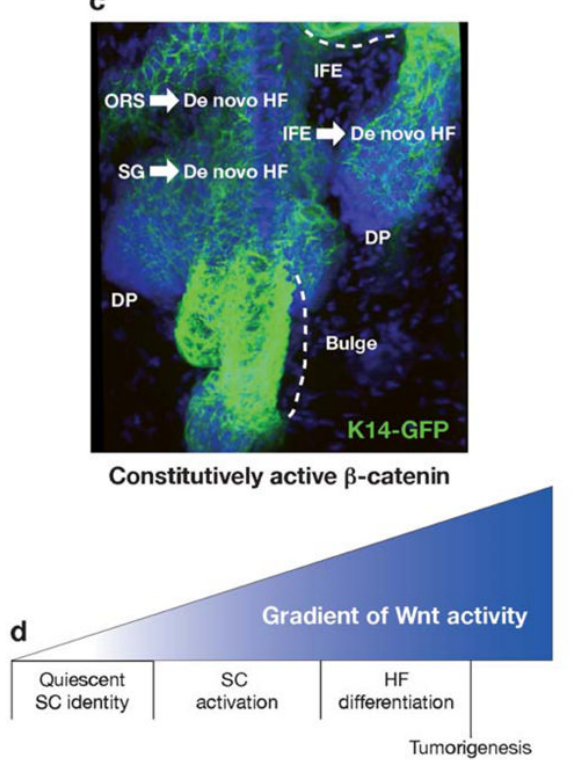

b
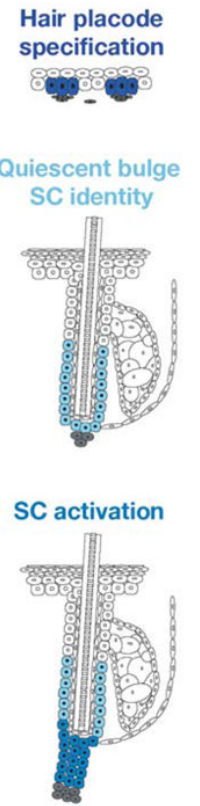

HF differentiation

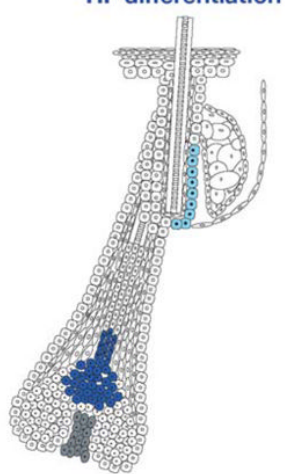

Figure 4.

The Wnt/ $\beta$-catenin signaling pathway during hair follicle (HF) morphogenesis and regeneration. (a) Schematic of the canonical Wnt pathway (for more details, see http://www.stanford.edu/\%7Ernusse/). In the absence of a Wnt signal, the excess of cytoplasmic $\beta$-catenin is targeted for degradation through its association with a multiprotein complex. Upon binding Wnt, its activated receptor complex recruits certain key components of the $\beta$-catenin degradation targeting machinery. Stabilized free cytoplasmic $\beta$-catenin is now translocated to the nucleus, where it can associate with transcription factors of the LEF/TCF family to transactivate the expression of their target genes. (b) Loss- and gain-of-function studies in mice have highlighted the different functions of $\mathrm{Wnt} / \beta$-catenin signaling during morphogenesis and adult skin homeostasis. During HF morphogenesis, Wnt/ $\beta$-catenin is required to specify the HF (placode) fate in the undifferentiated basal epidermis. During the adult hair cycle, Wnt/ $\beta$-catenin is required to maintain HF stem cell (SC) identity. As judged by a Wnt reporter transgene, an increase in Wnt signaling promotes SC activation to initiate the growth of a new hair during the telogen-to-anagen transition. An even stronger signal appears to be involved later at the transition of matrix cells to commit to terminally differentiate specifically along the hair shaft lineage. (c) When a constitutively active form of $\beta$-catenin is expressed for sustained periods in skin epidermis, mice develop de novo HFs from the interfollicular epidermis (IFE), outer root sheath (ORS), and sebaceous glands (SGs). 
Eventually, these mice develop HF tumors called pilomatricoma, which consist of immortalized matrix-like cells at the periphery, and pure hair cells in the centers (no inner root sheath or companion layer cells). Visualization was enhanced by breeding the K14- $\Delta \mathrm{N}$ mice on a background of K14-GFP mice. (d) The different signal strengths of Wnt reporter gene activity, combined with the $\beta$-catenin dosage dependency associated with these different outcomes in mice, can be explained by a model whereby the effective strength of Wnt signaling controls the behavior and fate of the follicle SC. Note: The so-called gradient of Wnt activity refers to the status of Tcf/Lef/ $\beta$-catenin transcriptional activity within the cell, which in fact could be achieved as a gradient, without even involving a Wnt per se. DP, dermal papilla. 
a

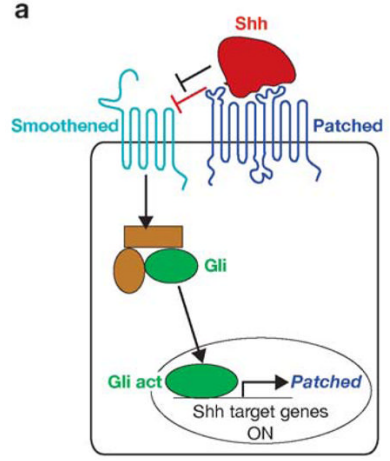

c

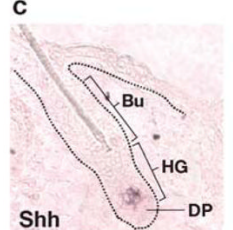

b

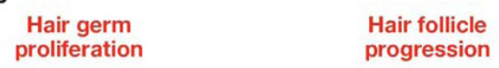

Embryo

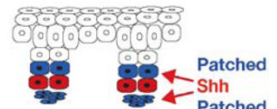

Adult
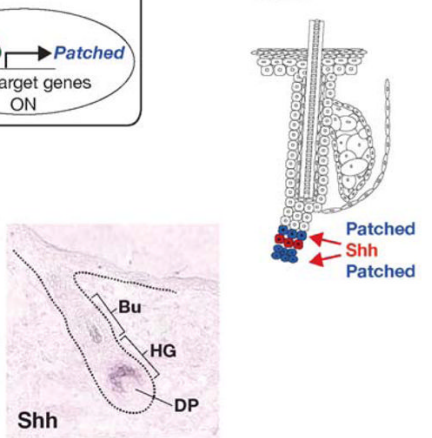

progression
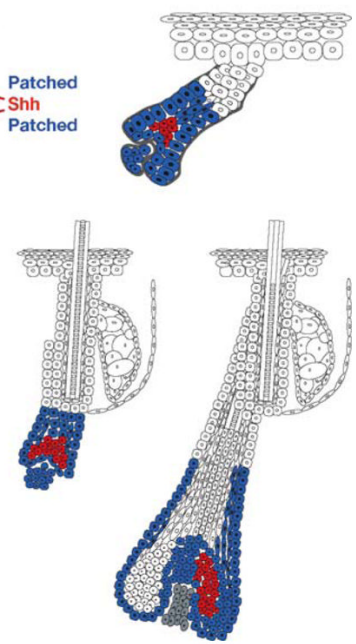

Figure 5.

The sonic hedgehog (Shh) signaling pathway during hair follicle morphogenesis and adult hair cycle. (a) Schematic of the Shh pathway. In the absence of Shh, its receptor Patched (Ptch) inhibits Smoothened (Smo) activity. Upon Shh binding, Ptch can no longer repress Smo, which activates the translocation of Gli into the nucleus, allowing it to transactivate its target genes. (b) The role of Shh in the hair follicle. Loss-of-function studies in mice have revealed the importance of Shh in sustaining proliferation in the embryonic and adult hair germ. Gain-offunction studies underscore the striking relation between basal cell carcinomas and deregulation of the Shh pathway. (c) Shh is not expressed in the quiescent bulge stem cells. During hair regeneration, there is a lag before Shh is strongly activated in the developing hair germ. Sustained expression of Shh seems to rely on close association with the dermal papilla (DP). Both in embryonic development and the adult, Shh appears to act downstream of the Wnt/ $\beta$-catenin signaling pathway. Bu, bulge; $\mathrm{HG}$, hair germ. 
a
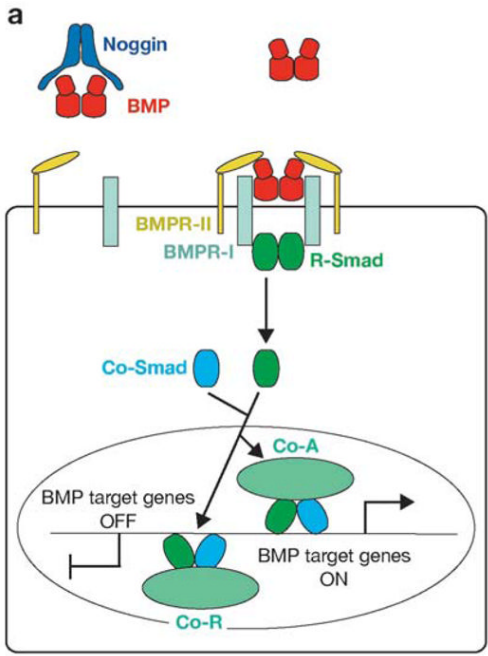

Hair placode specification

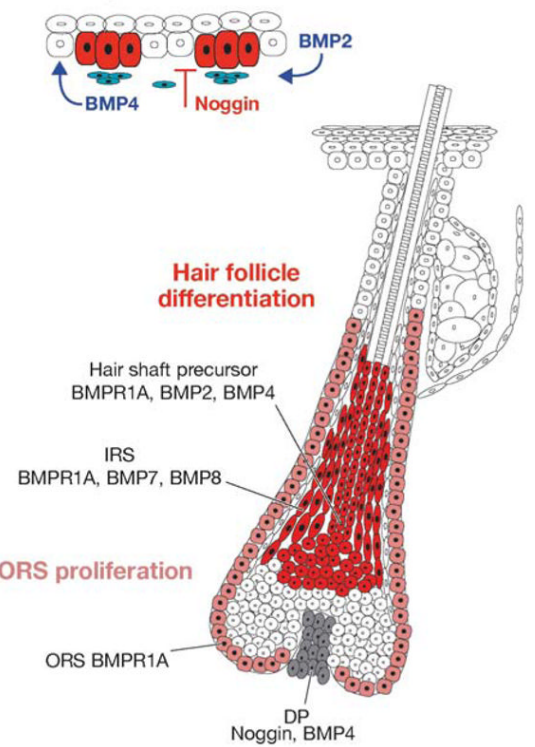

Figure 6.

Bone morphogenetic protein (BMP) signaling pathway during hair follicle morphogenesis and differentiation. (a) Schematic of the BMP pathway. The extracellular availability of BMP proteins is tightly regulated by soluble BMP inhibitors such as Noggin. BMP dimers bind a heterodimeric receptor complex (BMPR-I and BMPR-II) that phosphorylates and activates RSmad (Smads 1, 5, and 8), which then associates with its co-Smad (Smad 4) partner. Once activated, the R-Smad/co-Smad complex is translocated into the nucleus, where it transactivates its target genes. $(b)$ Role of BMPs in hair follicle morphogenesis. BMP signals are transmitted to and from the overlying epidermis to underlying dermal condensates.

Although the role these BMP signals play is not fully understood, this exchange of signaling is thought to play a role in the early specification of sites of hair follicle morphogenesis. As dermal condensates form, they express the BMP-inhibitor Noggin, which is required for normal follicle development and permissive for Lef1 expression and Wnt signaling. Later, as follicle maturation has progressed, the activation of BMP receptor signaling is essential for the matrix cells to differentiate to form the hair shaft and its inner root sheath (IRS) channel. BMP signaling also regulates epidermal proliferation in the skin. DP, dermal papilla. 


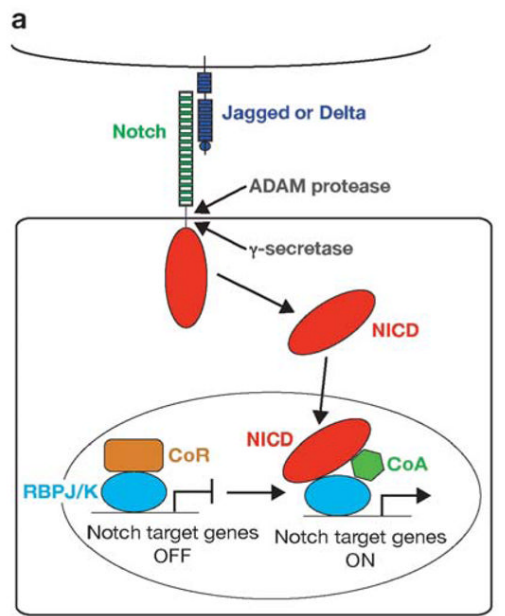

b

Epidermal differentiation

Active Notch 1 (NICD1)

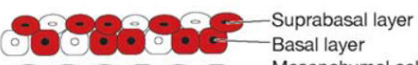

Mesenchymal cells

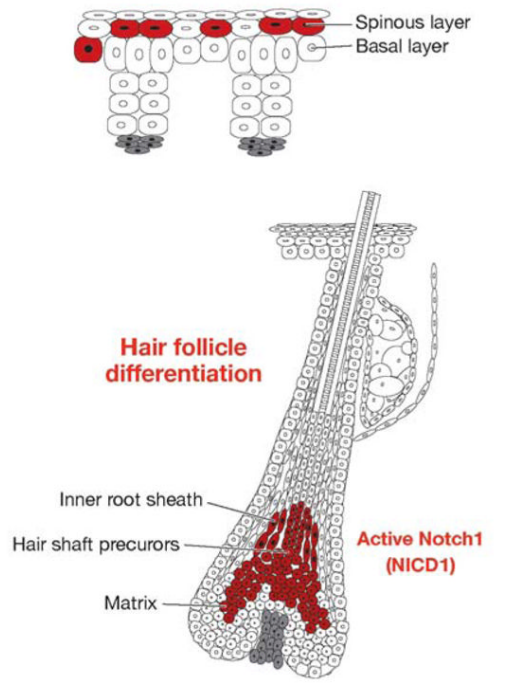

Figure 7.

Notch signaling pathway during epidermal stratification and hair follicle differentiation. (a) Schematic of canonical Notch signaling. Upon ligand (Jagged or Delta) binding, the Notch transmembrane receptor is cleaved by proteases (ADAM protease and $\gamma$-secretase), releasing the Notch intracellular domain (NICD), which can then translocate into the nucleus and associate with the DNA-binding protein RBP-Jk to permit transcription of target genes. $(b)$ Role of Notch1 in skin development. Notch1 is cleaved and generates its active form, NICD1, which controls epidermal stratification and differentiation. Early, NICD1 is present in basal cells but later it is found primarily in suprabasal cells. Loss-of-function studies suggest that Notch1 acts as a tumor suppressor in skin epidermis to restrict proliferation to the basal layer. Notch1 also plays a role in the hair follicle, where it has been demonstrated to play a critical role in the differentiation of the inner root sheath and the hair shaft. 


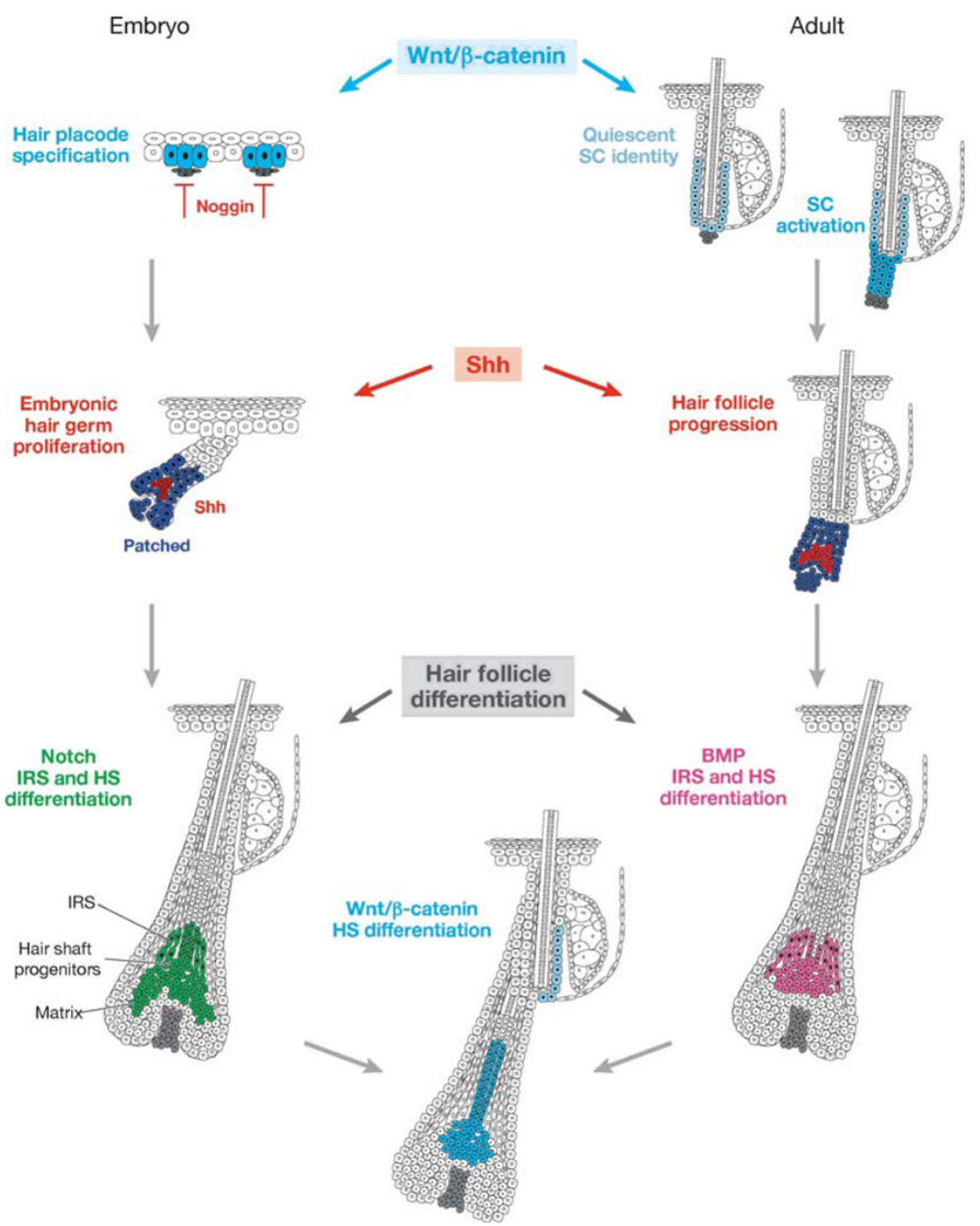

\section{Figure 8.}

Summary of the signaling pathways involved in hair follicle morphogenesis and regeneration. This schematic summarizes many of the signaling pathways involved in hair follicle morphogenesis and hair follicle regeneration. Wnt/ $\beta$-catenin signaling acts early in hair follicle specification and quiescent bulge stem cell (SC) activation. The sonic hedgehog (Shh) signaling pathway acts in the second step to promote embryonic and adult hair germ proliferation. Bone morphogenetic protein (BMP), Notch, and Wnt/ $\beta$-catenin signaling pathways act further downstream to allow the normal differentiation of matrix cells into the hair shaft (HS) and its inner root sheath (IRS) envelope. 